\title{
An Experimental Investigation of the Effect of Rock Wettability on the Performance of Carbonated Water Injection (CWI)
}

Jaime Castaneda ( $\sim$ joc1@hw.ac.uk)

Heriot Watt University

Almohannad Alghamdi

Heriot Watt University

Amir Farzaneh

Heriot Watt University

Mehran Sohrabi

Heriot Watt University

\section{Article}

Keywords: Wettability, Carbonated water injection, differential pressure, enhanced oil recovery, improved oil recovery

Posted Date: November 9th, 2020

DOl: https://doi.org/10.21203/rs.3.rs-98978/v1

License: (c) (i) This work is licensed under a Creative Commons Attribution 4.0 International License. Read Full License 


\title{
AN EXPERIMENTAL INVESTIGATION OF THE EFFECT OF ROCK WETTABILITY ON THE PERFORMANCE OF CARBONATED WATER INJECTION (CWI)
}

\author{
Authors \\ Jaime Castañeda; Data curation, Visualization, Investigation, Writing-Original Draft Preparation, Writing- \\ Reviewing and Editing. Almohannad Alhashboul: Visualization, Investigation. Amir Farzaneh: Laboratory \\ Conceptualization, Methodology, Supervision, and Mehran Sohrabi: Supervision.
}

Corresponding author: Jaime Castañeda

Heriot Watt University, School of Energy, Geoscience, Infrastructure and Society, EH14 4AS, Edinburgh, UK

\begin{abstract}
Wettability is often considered one of the most relevant variables in any conventional water injection process as it dominates the microscopic distribution of fluids in the porous medium, determines the amount of residual oil, and defines the ability with which a phase can flow. On the other hand, carbonated water injection is an enhanced oil recovery technique, where basically water saturated with $\mathrm{CO}_{2}$ is injected along the reservoir with the benefits of water displacement together with the benefits of $\mathrm{CO}_{2}$ injection, without the great disadvantages of poor sweeping causing low areal efficiency.

In addition, it has been proven that the transfer of $\mathrm{CO}_{2}$ from the aqueous phase to the oil phase, in one way, promotes the generation of what has been called a new gas phase, which is the main responsible for the incremental oil production, and which mainly attacks the residual oil saturation. Numerous experiments performed in the past on micro models, and plugs have shown that the injection of carbonated water plays an important role in the wettability of the rock. The injection has been demonstrated a change in the wettability to a water-wet because there is a reduction in the $\mathrm{pH}$ of the aqueous phase, and this is expected to modify the charges on the oil/water, and water/rock interfaces, and hence the wettability of the system. The dissolution of $\mathrm{CO}_{2}$, into the oil phase, and the destabilization of the polar components of the oil also may shift the wettability more towards waterwet, which favours a later water breakthrough, and a higher oil recovery factor. However, none of these experiments, as far as the author is informed, have been performed on whole cores, nor have these experiments used live crude oil with multi-component gases in solution, which would be closer to reality. This research seeks to close this gap by performing a new series of core floods to understand, from an engineering point of view, what effect the injection of carbonated water has on wettability in circumstances more realistic.
\end{abstract}

From these analyses it was concluded that rock wettability plays an important role on the differential pressure behaviour for both waterflooding, and carbonated water injection. A mix/oil-wet rock causes a greater differential pressure response. A much higher differential pressure is obtained when carbonated water injection is started. This is assumed to be due to the formation of the new gas phase. A greater oil recovery factor is obtained in a water-wet system when both secondary waterflooding, and tertiary CWI oil recovery are summed. However, when only tertiary injection of carbonated water is analysed, a higher oil recovery is obtained in mix/oil-wet systems. The new gas phase formation is facilitated in mix/oil-wet systems. The methane content dissolved in live oil plays the main role for oil recovery, and differential pressure behaviour in a carbonated water injection process. It is inversely related to the pressure behaviour, and oil recovery. This occurs because a low methane content allows a higher formation of the new gas phase, and therefore a higher production of oil; however, the differential pressure increases at the same time. Viscosity reduction due to $\mathrm{CO}_{2}$ mass transfer has a smaller effect in oil recovery, and differential pressure than the effect caused by the 
formation of a new gas phase. In the experiments that were conducted, the author calculated a novel linear relationship between new gas phase saturation, and tertiary oil recovery. This relationship is almost constant irrespective of the oil, and gas compositions and the wettability of the rock. This approach would allow the calculation of the additional tertiary oil recovery potential by the injection of carbonated water, based only on the saturation behaviour of the new gas phase; therefore the new objective of this recovery method would be to maximise the formation of this new phase. Although at laboratory scale there are different methods to determine the wettability of a rock, sometimes it is not possible to perform such measurements. Therefore, the author proposes a novel method that identifies trends in wettability, or better, compares trends based on Darcy's equation. This method was applied to the experiments conducted in this research, and its results were corroborated by other approaches available in the industry. Based on the results, it is possible to infer that by using a whole core the wettability change effect associated with the injection of carbonated water is not so preponderant, on the contrary, it could be more affected by the methane content in the system. The experiments conducted prior to this research had been focused on micro-models, and 1 to 2 inch diameter core evaluations, where the analysis was restricted to pore level or small scale behaviour, systems in which the impact of pore level wettability change is much greater.

\section{Keywords}

Wettability, Carbonated water injection, differential pressure, enhanced oil recovery, improved oil recovery.

\section{Introduction}

One of the properties that control the performance of waterflooding is the rock wettability. According to Honarpour et al. [1], wettability describes the relative attraction of one fluid for a solid in presence of other immiscible fluids. Wettability is the main reason for the distribution of microscopic fluid in the porous media, and, to a great extent, it determines the amount of residual oil saturation, and the ability of a particular phase to flow. The relative affinities of a rock to a hydrocarbon in the presence of water can be categorized as water-wet, mix-wet, or oil-wet systems. Commonly, wettability can be measured as follows, (1) by measuring the contact angle formed among the fluids, and a solid, flat surface; or quantifying the angle formed between the interface of the fluids within a capillary tube. The angle is measured through a denser fluid. It is referred to as "water-wet" if the mentioned angle is less than $90^{\circ}$, whereas an oil-wet system occurs when the angle is greater than $90^{\circ}$. Finally, a mixwet system is when the angle is equal to $90^{\circ}$; (2) by imbibition and forced displacement (Amott); and (3) the U.S. Bureau of Mines (USBM) wettability method. However, several other qualitative methods often are used [2], [3].

Wettability is influenced by fluid chemistry, polarity, molecular weights of the petroleum components, and the occurrence of chemical processes at the solid-fluid interface. Anderson [2] indicated that changes in the wettability of the cores could affect the electrical properties, capillary pressure, waterflood behaviour, relative permeability, dispersion, and simulated enhanced oil recovery.

Bobek et al. [4], summarised the importance of rock wettability based on his work, and the work of other authors, who found that preferentially water-wet cores flood more efficiently than oil-wet cores by waterflooding, which means that more oil can be recovered by water-wet systems.

Anderson [5], [6], researched how the wettability of the rock impacted capillary pressure, and relative permeability. He stated the capillary-pressure/saturation relationship depends on the interaction of wettability, pore structure, and saturation history. There is not a simple relationship that relates the capillary pressures determined at two different wettabilities. Relative permeabilities are a function 
of wettability, pore geometry, fluid distribution, saturation, and saturation history. Anderson [7], also conducted in depth, studies of the effects of wettability on waterflooding. He concluded that wettability affects waterflooding by controlling the flow, and spatial distribution of fluids in a porous medium. In a waterflooding controlled by a strong water-wet system at a moderate oil/water viscosity ratio, a large fraction of the original oil in place (OOIP) is recovered before the water breakthrough; however, after breakthrough, very little additional oil is produced. However, in a strong oil-wet system with a similar oil/water viscosity ratio, the water breakthrough occurs early, and more oil is produced after breakthrough. The experimental result obtained by Anderson [7] also indicated that high oil/water viscosity ratios cause a decrease in oil recovery at breakthrough. However, high oil recovery will be obtained at breakthrough time, even in a strong oil-wet system, when the oil/water viscosity ratio is very favourable. In a mix-wet system, the larger pores of the rock are filled with oil, and they are oil-wet; the smaller pores are filled with water, and they are water-wet.

According to Sohrabi et al. [8], carbonated water injection reduces the $\mathrm{pH}$ of the aqueous phase, and this is expected to change the charges on the oil/water, and water/rock interfaces, and hence the wettability of the system. The dissolution of $\mathrm{CO}_{2}$, into the oil phase, and the destabilization of the polar components of the oil also may shift the wettability more towards water-wet [8], [9], [10], which favours a later water breakthrough, and a higher oil recovery factor.

Mat Ali et al. [11], and Seyyedi et al. [12], [13] stated that if the concentration of $\mathrm{CO}_{2}$ is increased, the wettability of the rock is changed from weakly water-wet to water-wet. Furthermore, Seyyedi [12] identified that the composition of the rock is also a major factor that defines wettability during the carbonated water injection process. The results of their study suggested that (1) in unaged quartz, the alteration of the wettability occurs because of the decrease in the $\mathrm{pH}$ of the brine after the dissolution of the $\mathrm{CO}_{2}$, which changes the wettability toward neutral-wet; (2) the $\mathrm{CO}_{2}$ dissolved in the brine on the unaged calcite caused some dissolution of the calcite as well as altering the wettability toward more water-wet; and (3) the aged minerals were affected to a greater extent by carbonated water injection than the unaged minerals. In addition, Sanaei et al. [14] concluded that the dissolution of calcite results in the generation of "wormholes" rather than altering the wettability. The change in the wettability was proven by direct micro model observations [15], determination of the contact angle [12], and the sessile drop technique [11].

Mosavat et al. [16] performed carbonated water injection experiments at pore scale level in oil-wet to neutral-wet micro models. Their findings indicated that the main oil-trapping mechanism was wettability trapping. Their observations also revealed that the wettability of the system was modified gradually as the carbonated water injection proceeded towards the water-wet condition. This alteration is believed to be initiated by the diffusion of $\mathrm{CO}_{2}$ from the aqueous phase to the oil phase. After the $\mathrm{CO}_{2}$ molecules reach the surface of the rock that has been contacted by oil, they begin to replace the oil molecules (which initially make the system oil-wet); this gradual replacement causes the wettability of the surface of the rock to shift toward the water-wet condition.

The carbonated water core flooding experiments conducted by Sohrabi et al. [15] in 2-inch samples indicated that higher oil recovery was obtained with mixed-wet systems than with water-wet systems. Mahzari et al. [17] conducted their experiments in a composite carbonate core; they determined that wettability regimes during the injection of water, and carbonated water were similar, so the carbonated seawater would not alter the wettability state in carbonate rocks.

Despite all the above, none of the experiments performed so far by other authors estimated the effect of carbonated water injection when it is conducted at different wetting conditions under the following characteristics considered as being novel: (1) when a whole core is used, and (2) when the reservoir fluids are more similar to reality by using a live crude oil with a multi-component dissolved gas. All the previous executed under reservoir conditions. 


\section{Experimental procedure}

The purpose of the experimental section was to maintain, throughout each of the experiments, as many experimental parameters as possible constant, to evaluate more effectively the effect of a specific variable during the injection of carbonated water. Based on the above, different experiments were designed so as not to modify the following parameters:

i. Core sample. For each of the experiments, the same sandstone core (4-inches whole core) literally always was used.

ii. Temperature and pressure. During each of the experiments the pressure and temperature was remain unaltered and the same for all experiments.

iii. Composition of the brine. A brine is required to displace the crude oil inside the core, either for conventional water injection, or for the injection of carbonated water. In the process of making the brine, the same chemical composition was always used.

iv. $\quad \mathrm{CO}_{2}$ concentration. Carbonated water was always fully saturated with $\mathrm{CO}_{2}$. The $\mathrm{CO}_{2}$ was always supplied by the same manufacturer.

v. Experimental equipment. The same rig, pumps, cells, and transfer lines were used in each of the experiments, with the purpose of minimising the error associated with changes in dead volumes, power and/or efficiency.

It is understood that an approach of this nature is complex to implement mainly because this experimental phase requires a considerable time of execution. However, this method is considered correct in the evaluation of carbonated water injection, since it is possible to understand how specific reservoir parameters affect the results of carbonated water injection under more realistic reservoir conditions. Table 1 presents a summary of the experiments that were performed.

Table 1. CWI experiments that were performed to understand wettability effect

\begin{tabular}{|c|l|l|l|}
\hline Experiment & \multicolumn{1}{|c|}{ Dead oil } & \multicolumn{1}{|c|}{$\begin{array}{c}\text { Multi-component } \\
\text { dissolved gas }\end{array}$} & Rock wettability \\
\hline 1 & Heavier oil & $100 \%$ methane content & Water-wet \\
\hline 4 & Heavier oil & $100 \%$ methane content & Non-water-wet \\
\hline 5 & Lighter oil & $75 \%$ methane content & Non-water-wet \\
\hline 6 & Lighter oil & $75 \%$ methane content & Water-wet \\
\hline 9 & Lighter oil & $47 \%$ methane content & Water-wet \\
\hline 10 & Lighter oil & $47 \%$ methane content & Non-water-wet \\
\hline
\end{tabular}

To conduct this research, six different experiments were performed at $140^{\circ} \mathrm{F}$, and $1200 \mathrm{psi}$. The same whole core, heavier live oil, brine, and carbonated water composition were used in two experiments. However, four additional experiments were conducted by using a lighter live oil instead of the heavier live oil. Each experiment consisted of injecting methane pre-equilibrated brine, mimicking a secondary waterflooding process, until no more oil production was obtained; the injection rate was established at $14 \mathrm{cc} / \mathrm{hr}$, which guaranteed a laminar flow. Immediately after the conventional secondary waterflooding was finished, the injection of carbonated water was initiated 
using a tertiary injection scenario. The tertiary carbonated water injection maintained the same injection rate, and direction until no more oil is being produced. Three of the six experiments were conducted based on a water-wet scenario, while the other three were completed under non-water-wet conditions. In this section, the term non-water-wet will be consistently referred to instead of oil-wet, or mix-wet. This is because it was not possible to conventionally measure the wettability of the rock during each experiment that was performed under ageing conditions, thus, to avoid inaccuracies, it was considered that this term could be more accurate.

\subsection{High pressure - high temperature rig}

Figure 1, present a diagram of the high-pressure, high-temperature core flooding rig that was used to perform the experiments. The equipment consists of the following components:

i. A Hassler-type core holder.

ii. Two pressure transducers.

iii. A back-pressure regulator.

iv. Transfer lines.

v. A separator.

vi. A gasometer.

vii. A graduated cylinder.

viii. Different cells to be filled with oil, brine, and carbonated water.

ix. Series of dual pumps.

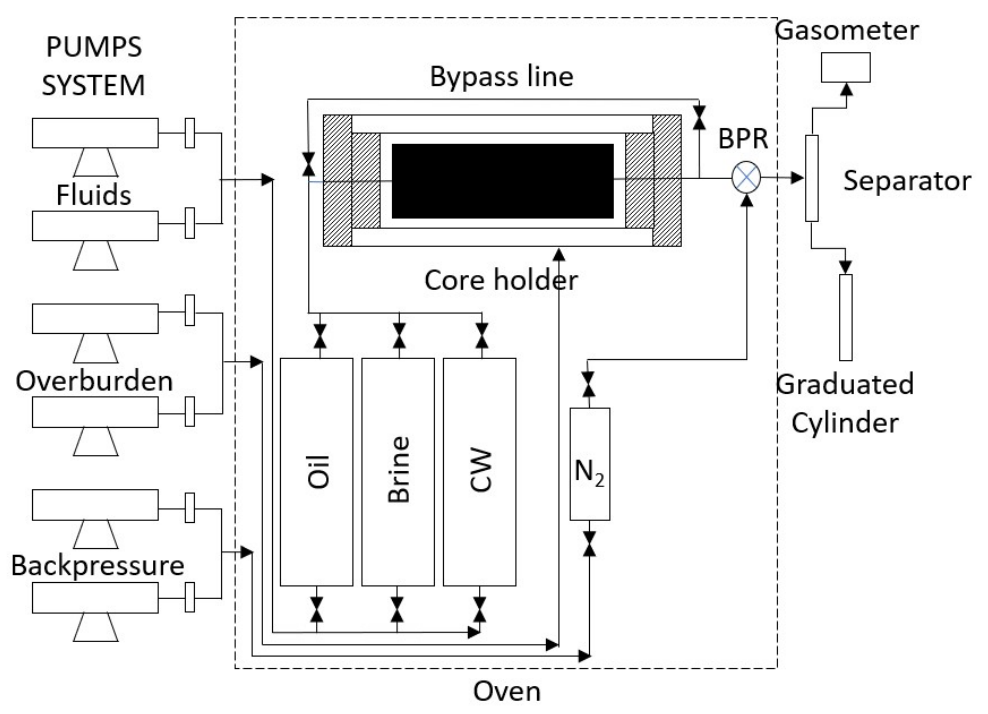

Figure 1. Schematic of the core flood rig used in the core flood experiments

The series of dual pumps system are divided into three subsystems that control (1) the injection of fluids into the core, (2) the overburden pressure of the core, and (3) the back-pressure regulator (BPR). The injection system was connected to the fluid transfer vessels, which were used to inject the fluids into the core at high pressure. Effluents from the core was moved through a BPR which reduced the pressure to atmospheric pressure. The dissolved gas, and liquids were separated and measured independently using a gasometer and a graduated cylinder, respectively. The overburden pressure 
was set at experimental conditions and was controlled by the dual pumps during the core flooding experiments.

Transducers were installed at the inlet, and outlet of the core holder, to measure the pressure in real time at each point, and thus to determine the differential pressure along the core. They have the capacity to automatically capture pressure measurements at time intervals of even less than one second. The resulting data was continuously collected, recorded, and displayed on a computer monitor, which had a built-in data acquisition system for subsequent analysis. In addition, a bypass line was used to measure the dissolved gas content of both, live oil, and water injected preceding each stage of the experiments, with the purpose of validating pre-acquired measurements.

The temperature of the experiments was controlled by maintaining the whole assembly inside a heated oven, such temperature is controlled automatically in accordance with the needs of each experiment. The core orientation was horizontal for the experiments reported in this document. The experiments were conducted at a temperature of $140^{\circ} \mathrm{F}$ and a pressure of $1200 \mathrm{psi}$. The overburden pressure was stablished at 2000 psi.

\subsection{Core sample}

Table 2 presents a list of the properties of the core sample used in these experiments. The sandstone core, whose main component is quartz, was taken from a block of Clashach rock available at the university laboratory. Helium was used to determine the porosity of the core, and its permeability was measured by flowing brine through the core at experimental conditions, i.e. a core pressure of $1200 \mathrm{psi}$ and a core temperature of $140^{\circ} \mathrm{F}$. The pore volume of the core was determined as the total of fluid to saturate the core.

Table 2. Properties of the core sample

\begin{tabular}{|c|c|}
\hline Property & Value \\
\hline Length & $29.1 \mathrm{~cm}$ \\
\hline Diameter & $10.3 \mathrm{~cm}$ \\
\hline Porosity & $13.2 \%$ \\
\hline Permeability & $105 \mathrm{md}$ \\
\hline Pore volume & 321 \\
\hline
\end{tabular}

\subsection{Fluids}

\subsubsection{Brine and carbonated water samples}

A unique brine composition was used in the experiments performed in this research. The brine is a synthetic seawater brine, and Table 3 provides its chemical composition. 
Table 3. Chemical composition of the brine

\begin{tabular}{|c|c|}
\hline Ion & $\begin{array}{c}\text { Parts per } \\
\text { million (ppm) }\end{array}$ \\
\hline $\mathrm{Na}$ & 16844 \\
\hline $\mathrm{Ca}$ & 664 \\
\hline $\mathrm{Mg}$ & 2279 \\
\hline $\mathrm{SO}_{4}$ & 3560 \\
\hline $\mathrm{Cl}$ & 31107 \\
\hline $\mathrm{HCO}_{3}$ & 193 \\
\hline $\mathrm{TDS}$ & 54597 \\
\hline
\end{tabular}

On the other hand, the carbonated water, which was fully saturated with $\mathrm{CO}_{2}$, was also made using the brine composition presented in Table 3. The viscosities of the brine, and of the carbonated water at the experimental conditions, i.e., $140{ }^{\circ} \mathrm{F}$, and $1200 \mathrm{psi}$, were measured in the laboratory by a capillary viscosimeter, and their values are provided in Table 4.

Table 4. Brine viscosity values

\begin{tabular}{|c|c|}
\hline Fluid & Viscosity (cP) \\
\hline Brine & 0.485 \\
\hline $\begin{array}{c}\text { Carbonated } \\
\text { water }\end{array}$ & 0.502 \\
\hline
\end{tabular}

\subsubsection{Oil samples}

Two crude dead-oil samples from the same field but different wells were used in the core flood experiments. Despite the fact that both crudes come from the same reservoir, there are small differences between their chemical composition, which has allowed us to slightly differentiate between them, and thus, name one of the crudes as the lighter one, and the other as the heavier one. The compositions of the dead oils are presented in Figure 2.

For this research, the viscosity of the live oil was affected mainly by the lower carbon content, which ranged for this case, from $\mathrm{C}_{2}$ to $\mathrm{C}_{5}$; the live oils that had a higher content of $\mathrm{C}_{2}-\mathrm{C}_{5}$ had lower viscosities. Table 5 presents the values of the viscosities of the recombined oils that were measured at the experimental conditions, i.e., $140{ }^{\circ} \mathrm{F}$, and 1200 psi according to the information presented in the previous plot. 


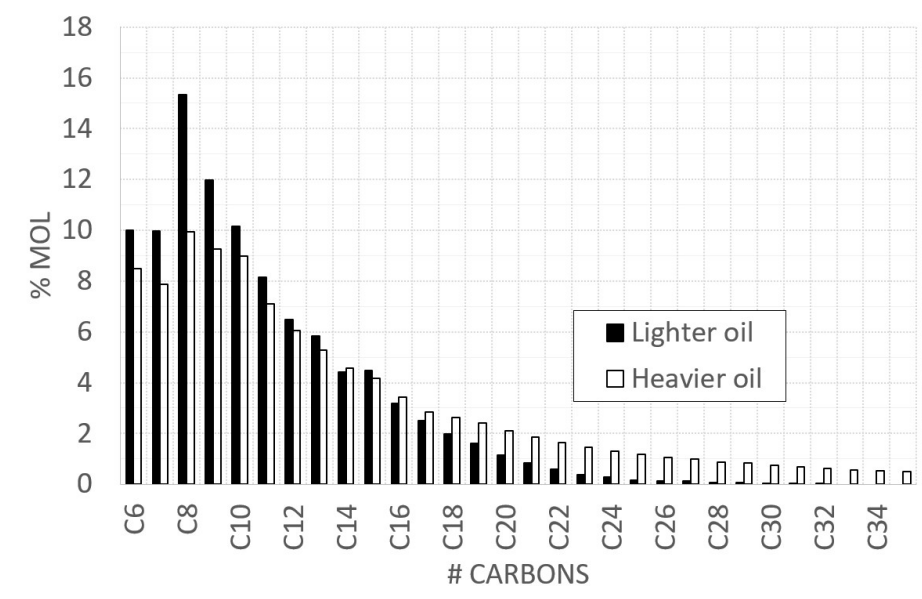

Figure 2. Compositions of the lighter and heavier dead oil

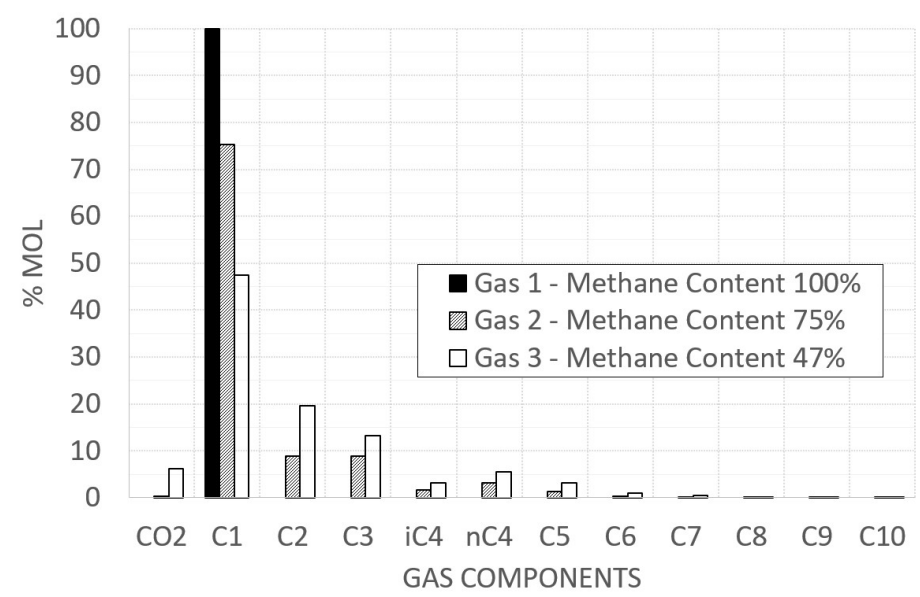

Figure 3. Gas compositions

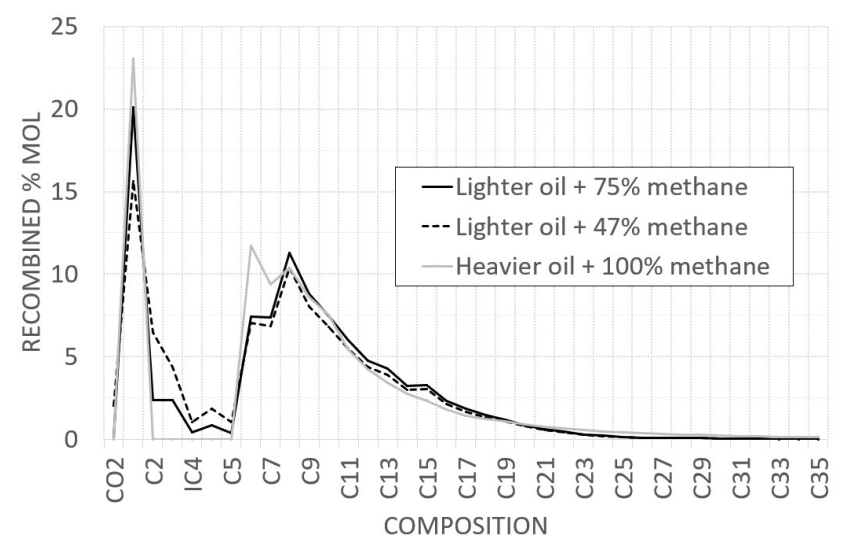

Figure 4. Compositions of the three recombined live oil used in the core flooding experiments 
Table 5. Viscosity values of the recombined live and dead oil $(*$ Not Measured $)$

\begin{tabular}{|l|c|c|c|}
\hline Methane content of the gas & $100 \%$ & $75 \%$ & $47 \%$ \\
\hline Recombined methane content & $23 \%$ & $20 \%$ & $16 \%$ \\
\hline Lighter dead oil (cP) & \multicolumn{3}{|c|}{1.58} \\
\hline Lighter live oil (cP) & $\mathrm{NM}^{*}$ & 0.87 & 0.70 \\
\hline Heavier dead oil (cP) & \multicolumn{3}{|c|}{1.90} \\
\hline Heavier live oil (cP) & 1.14 & $\mathrm{NM}^{*}$ & $\mathrm{NM}^{*}$ \\
\hline
\end{tabular}

\subsection{Fluids preparation}

Three main fluids were prepared for the core flood experiments: (1) brine, (2) carbonated water, and (3) live oil.

\subsubsection{Brine preparation}

The brine was prepared to maintain concentrations, and compositions presented in Table 3. During the early phase of design, and execution of some experiments, methane was considered as the unique gas in solution contained in the crude oil. Consequently, the brine was also fully pre-equilibrated with methane to prevent mass transfer during conventional water injection. Because both fluids were fully saturated with methane, the risk of mass transfer would be minimized.

Through the performance of the experiments, and their results, it was identified that the presence of methane dissolved in the crude oil influenced the results of carbonated water injection. Therefore, it was decided to extend the scope of this research to assess more complex gases dissolved in the crude oil, which implied that the methane content in the crude oil would no longer be $100 \%$. As a result, the development of this research was placed at a crossroads, since two options were being considered.

The first option consisted in pre-equilibrating the brine with each one of the defined gases according to the experiment under evaluation on that moment; in other words, if an experiment with a $75 \%$ methane content as solution gas was being performed, the brine would be pre-equilibrated with the same gas of $75 \%$ methane content. Theoretically, with this option, there should be no mass transfer in the conventional water injection phase. However, after the conventional water injection, the rockfluid system would be rich in a complex gas, since this gas is dissolved within the brine, and it may in future interact with the $\mathrm{CO}_{2}$ coming from the carbonated water in unresearched or unknown forms, and therefore mask the real results of the carbonated water injection.

The second option consists in keeping the injection brine pre-equilibrated with methane, while the crude oil has a dissolved gas of greater complexity. This option could result in a mass transfer of the lighter components; however this effect was considered to be minimal, because, the maximum concentration of methane contained in the brine was $2.5 \mathrm{cc}$ of gas per $\mathrm{cc}$ of brine at experimental conditions, which was considered relatively low value; while the concentration of gas in solution within the crude oil would range between $36-82 \mathrm{cc}$ of gas per cc of oil. An important advantage of this option, is that the composition of the brine would be kept the same for the experiments that had already been performed, and for the upcoming new ones, which would facilitate the comparison of the results of the different experiments. For this reason, this second option has been chosen. 
To ensure a full saturation of the methane in the brine, at experimental conditions, the system was over-saturated. Thus, in the brine cell to be injected into the core, at a pressure of $1200 \mathrm{psi}$, and a temperature of $140{ }^{\circ} \mathrm{F}$, there would exist a small gas cap, which would later be produced using the bypass line. Therefore, it was confirmed that under the experimental conditions mentioned above, the brine would be fully saturated with methane.

\subsubsection{Carbonated water preparation}

To prepare the carbonated water, the brine previously defined has been used as a base, to which carbon dioxide is later added. Considering that a fully saturated $\mathrm{CO}_{2}$ system was defined as a premise for these experiments, a cell was filled with $950 \mathrm{cc}$ of brine at room conditions, and then $50 \mathrm{cc}$ of $\mathrm{CO} 2$ was added at experimental conditions, i.e. $140{ }^{\circ} \mathrm{F}$ and $1200 \mathrm{psi}$.

Subsequently, the entire system is brought to the experimental conditions where it is maintained until equilibrium is reached. With the above considerations, a small gas cap was generated, indicating an oversaturation of the system, which was produced before the experiment was started using a by-pass line. The gas-brine ratio was calculated at $18 \mathrm{cc}$ of $\mathrm{CO}_{2}$ per $\mathrm{cc}$ of brine.

\subsubsection{Live oil preparation}

Multiple combinations of live oil were possible; since there were two samples of dead oil, and three samples of solution gas. However, this research only used three possible combinations, and therefore only three types of live oil were analysed.

\subsubsection{Heavier oil - single component gas, methane fully saturated}

$1000 \mathrm{cc}$ of the heavier oil, and $771 \mathrm{cc}$ of methane, were mixed in a rocking cell to prepare the live oil. The bottom side of the rocking cell was connected to a pump, which maintained the pressure of the system inside the cell constant at $1200 \mathrm{psi}$. The rocking cell was also equipped with a heating jacket to ensure that the temperature of the fluid was maintained at $140^{\circ} \mathrm{F}$.

Both oil, and gas were mixed over a long period of time, while the pressure, and temperature of the rocking cell were maintained at experimental conditions. Observing the pressure behaviour on the bottom side of the rocking cell until it was constant, i.e. until there was no change in volume, is considered a good indication that the equilibrium in the system has been reached.

A mass transfer in the system is expected in the initial phase of the mixing process, causing a variation in the pressure inside the rocking cell; therefore, the pump will start injecting, or retracting to keep the pressure inside the cell constant at 1200 psi.

By the time equilibrium is finally reached, there will be no more mass transfer, and consequently the pump will no longer inject or retract. With the above specifications, the system was ensured to be over-saturated with methane, which formed a small gas cap that was then produced through the bypass line. The GOR of live oil ranged from 36 to $42 \mathrm{cc}$ of gas per cc of oil.

\subsubsection{Lighter oil - multi-component gas, methane content: $75 \%$, fully saturated}

$1000 \mathrm{cc}$ of the lighter oil, and $400 \mathrm{cc}$ of a multi-component gas were mixed in a rocking cell to prepare a new version of live oil, until equilibrium was reached in the manner previously described. Pressure, and temperature were again set at $1200 \mathrm{psi}$, and $140^{\circ} \mathrm{F}$, respectively. 
The gas cap formed by the oversaturation of the system was also released before the experiment started through the bypass line, and the GOR of this live oil ranged from 63 to $70 \mathrm{cc}$ of gas per $\mathrm{cc}$ of oil. The gas composition is presented in Table 6 .

Table 6. Multi-component gas composition, methane content: $75 \%$, fully saturated. Volumes at $2260 \mathrm{psi}$, and $68^{\circ} \mathrm{F}$

\begin{tabular}{|l|c|}
\hline Component & Required Volume (cc) \\
\hline $\mathrm{CO}_{2}$ & 1.13 \\
\hline $\mathrm{C}_{1}$ & 819.37 \\
\hline $\mathrm{C}_{2}$ & 55.12 \\
\hline $\mathrm{C}_{3}$ & 63.90 \\
\hline $\mathrm{iC}_{4}$ & 13.84 \\
\hline $\mathrm{nC}_{4}$ & 25.92 \\
\hline $\mathrm{C}_{5}$ & 12.73 \\
\hline $\mathrm{C}_{6}$ & 3.65 \\
\hline $\mathrm{C}_{7}$ & 2.61 \\
\hline $\mathrm{C}_{8}$ & 1.24 \\
\hline $\mathrm{C}_{9}$ & 0.30 \\
\hline $\mathrm{C}_{10}$ & 0.17 \\
\hline
\end{tabular}

\subsubsection{Lighter oil - multi-component gas, methane content: $47 \%$, fully saturated}

$1000 \mathrm{cc}$ of the lighter oil, and $214 \mathrm{cc}$ of a multi-component gas were mixed in a rocking cell to prepare the third version of live oil, until equilibrium was reached in the manner previously described. Same as above, pressure, and temperature were stabilised at $1200 \mathrm{psi}$, and $140^{\circ} \mathrm{F}$, respectively.

The gas cap formed by the oversaturation of the system was also released before the experiment started through the bypass line, and the GOR of this live oil ranged from 78 to $83 \mathrm{cc}$ of gas per cc of oil. Multi-component gas composition used for this version is presented in Table 7.

Table 7. Multi-component gas composition, methane content: $47 \%$, fully saturated. Volumes at $4425 \mathrm{psi}$, and $68^{\circ} \mathrm{F}$

\begin{tabular}{|c|c|}
\hline Component & Required Volume (cc) \\
\hline $\mathrm{CO}_{2}$ & 36.40 \\
\hline $\mathrm{C}_{1}$ & 461.71 \\
\hline $\mathrm{C}_{2}$ & 174.01 \\
\hline $\mathrm{C}_{3}$ & 141.17 \\
\hline $\mathrm{iC}_{4}$ & 37.96 \\
\hline
\end{tabular}




\begin{tabular}{|c|c|}
$\mathrm{nC}_{4}$ & 72.12 \\
\hline $\mathrm{C}_{5}$ & 46.35 \\
\hline $\mathrm{C}_{6}$ & 16.50 \\
\hline $\mathrm{C}_{7}$ & 8.30 \\
\hline $\mathrm{C}_{8}$ & 4.53 \\
\hline $\mathrm{C}_{9}$ & 0.77 \\
\hline $\mathrm{C}_{10}$ & 0.19 \\
\hline
\end{tabular}

\subsection{Core preparation}

Before each of the experiments is started, a meticulous procedure of core cleaning is conducted with the purpose of ensuring, as far as possible, to reach the original conditions of the core status. Figure 5 , and Figure 6 present a graphic summary of the procedure performed for the correct preparation of the core.

This procedure is conducted before the beginning of the carbonated water injection experiments, at unaged, and aged conditions, respectively. The procedure can be summarized as follows:

i. After each experiment, some fluids, i.e. carbonated water, residual oil, and irreducible water are still contained within the core. With the purpose of removing all of these, different batches of toluene, methanol, and a mixture of the two are injected until clean effluents are obtained.

ii. The whole core is then fully saturated with the formation brine, and brine permeability was calculated.

iii. As a next step, two pore volumes of N4000 (a high viscosity fluid) are injected through the core. This fluid will displace the brine inside the core, except for the irreducible water. Thus, based on a volumetric balance, it is possible to calculate the connate water saturation.

iv. A heavy mineral oil (HMO) is then injected through the core to displace the high viscosity N4000 fluid. The injection is finalized when no more N4000 is produced in the effluents.

v. A light mineral oil (LMO) is then injected through the core until no more $\mathrm{HMO}$ is produced in the effluents.

vi. Three porous volumes of kerosene are injected through the core at low injection rates to displace the LMO.

vii. Dead oil injection starts.

viii. Finally, when the core is fully saturated with dead oil, two pore volumes of live oil are injected. A live oil permeability is calculated.

Depending on the experimental requirements, an ageing process may be necessary for the core. If an aged core is required, then an injection of dead oil at a very low rate $(1 \mathrm{cc} / \mathrm{hr})$ is mandatory, with this in mind, this kind of experiments will need an additional month to guarantee the wettability change to a non-water wet.

Additionally, further analysis will show that the ageing process was effective, and that there was indeed a change in the wettability of the rock after the ageing process. The success of this ageing process will also be demonstrated by the behaviour in the production curves.

The aging process consisted of injecting dead oil for 35 days at a very low rate $(1 \mathrm{cc} / \mathrm{hr})$. After each experiment, the whole core was cleaned with multiple batches of toluene and methanol as explained in a previous section. 
Connate water saturation was measured by differential volumes, after saturating the entire core with brine, and then displacing the brine with a high viscosity fluid. For all cases, the connate water saturation ranged between $13.3 \%$, and $15.4 \%$. A high viscosity fluid was displaced by heavy mineral oil, which subsequently was displaced by light mineral oil, and kerosene.

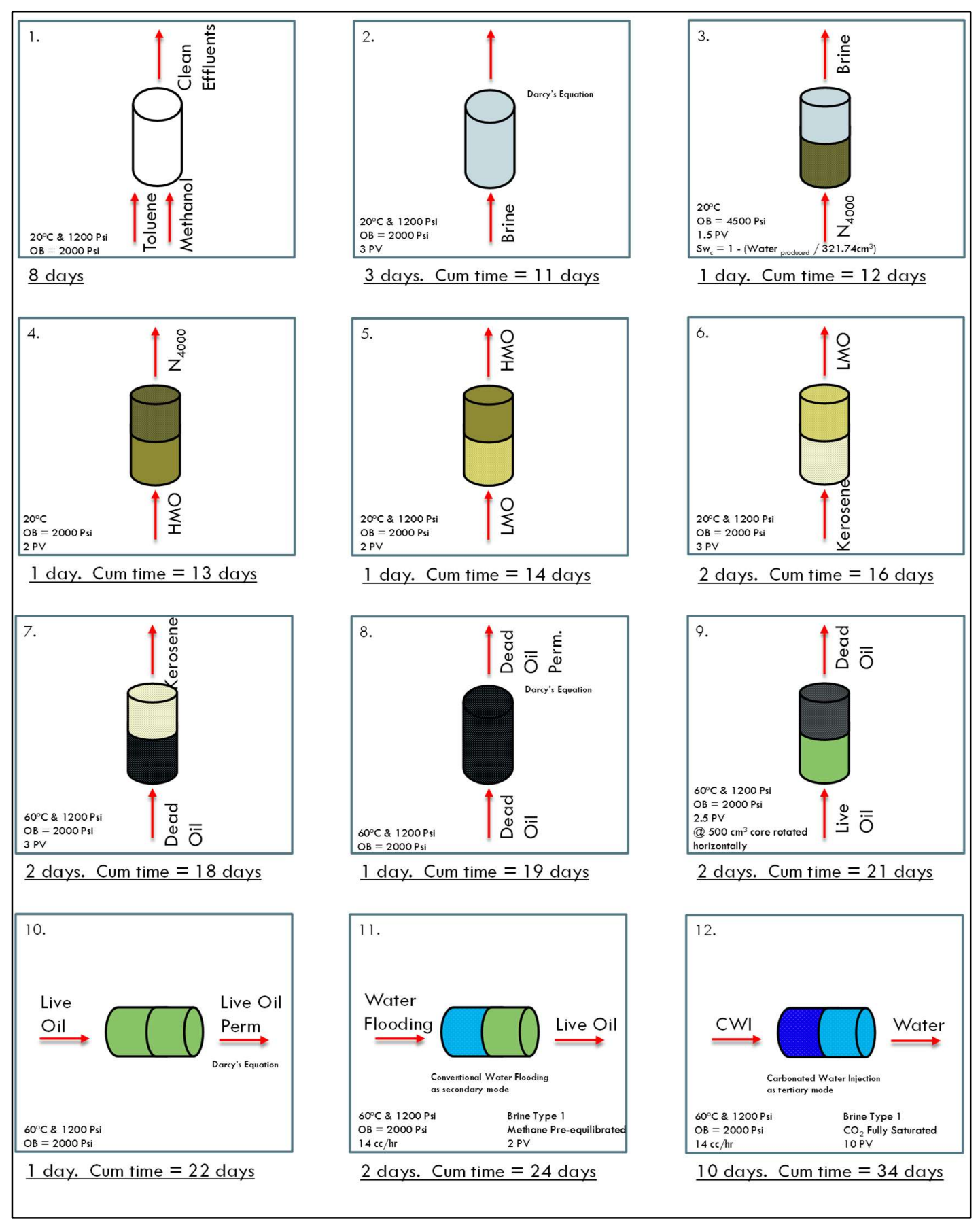

Figure 5. Core preparation for a carbonated water injection experiment under unaged conditions 


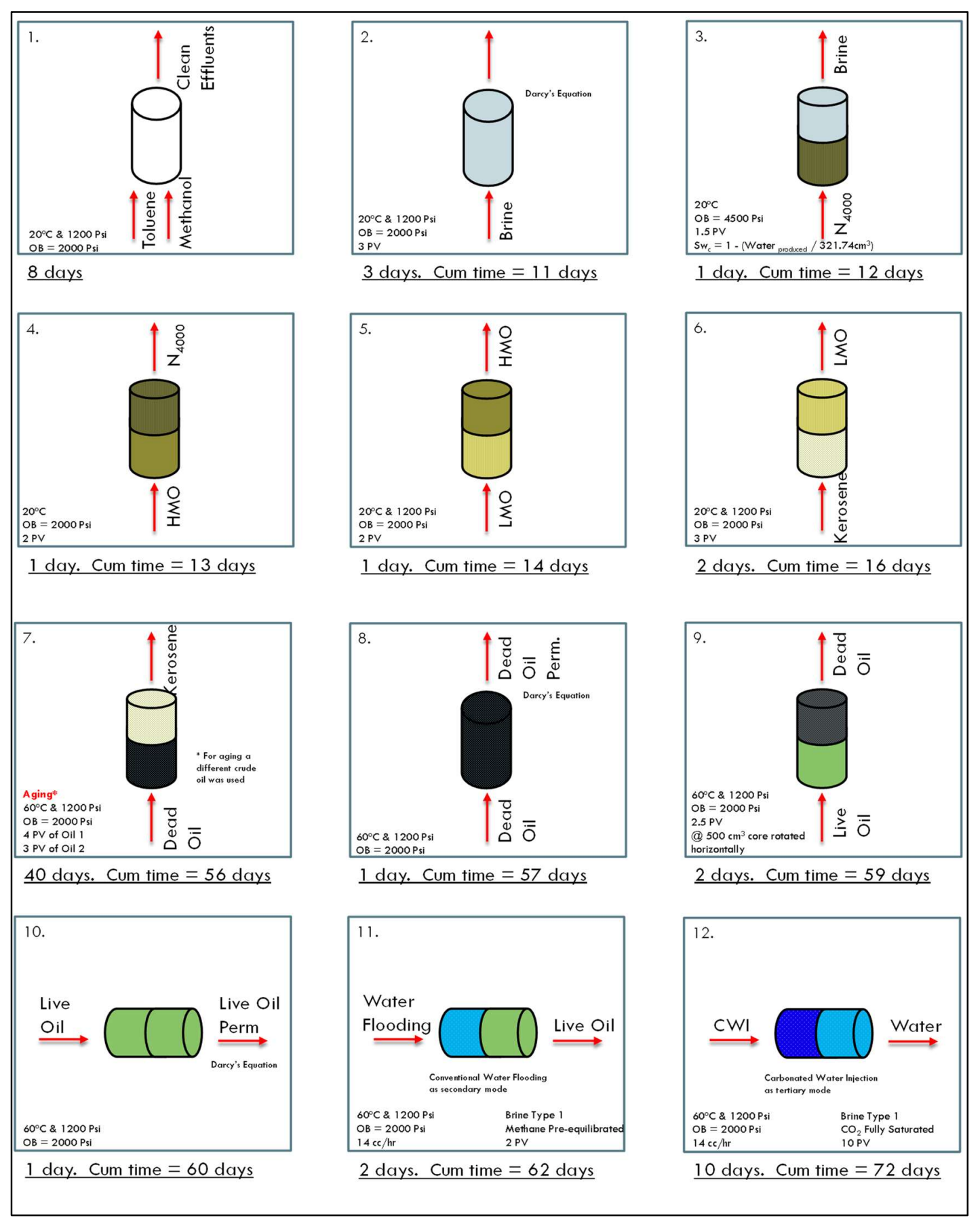

Figure 6. Core preparation for a carbonated water injection experiment under aged conditions.

For a water-wet system, dead oil was injected for 2 days; however, if a non-water-wet system is required, the dead oil is injected for 35 days. Finally, the core is saturated with live oil, and it is ready to start the secondary conventional waterflooding. A number of methods used to determine the wettability of a system are based on the value of the connate water saturation [18]. However, considering the procedure for the preparation of the core presented in Figure 5, and Figure 6, the calculation of the connate water saturation is determined before the ageing process, even before 
injecting any drop of oil into the system. Therefore, in general terms, the values of connate water saturation are similar, because at this point the experimental conditions of all experiments can be considered practically identical, resulting a small variation in the connate saturation values. For this research, the connate water saturation values are in the range of $13.4 \%$, and $15.4 \%$, Table 8 .

Table 8. Connate water saturation for the core flooding experiments

\begin{tabular}{|l|l|l|c|}
\hline & \multicolumn{1}{|c|}{ Dead Oil } & \multicolumn{1}{|c|}{ Gas in solution } & Connate water saturation \\
\hline Exp 1 & Heavier oil & $\mathrm{CH}_{4} .100 \%$ & $15,4 \%$ \\
\hline Exp 4 & Heavier oil & $\mathrm{CH}_{4} . \quad 100 \%$ & $13,4 \%$ \\
\hline Exp 5 & Lighter oil & Multicomponent. $\mathrm{CH}_{4} 75 \%$ & $14,9 \%$ \\
\hline Exp 6 & Lighter oil & Multicomponent. $\mathrm{CH}_{4} 75 \%$ & $13.9 \%$ \\
\hline Exp 9 & Lighter oil & Multicomponent. $\mathrm{CH}_{4} 47 \%$ & $14,4 \%$ \\
\hline Exp 10 & Lighter oil & Multicomponent. $\mathrm{CH}_{4} 47 \%$ & $14,3 \%$ \\
\hline
\end{tabular}

\section{Wettability analysis}

\subsection{Determination of wettability. Differential pressure method.}

As previously mentioned, it was not possible to conventionally measure the wettability of the rock in these experiments. However, using qualitative analysis, it is possible to identify a wettability trend. To verify the change in the rock wettability after the ageing process, it was considered as an indirect measure the behaviour of the differential pressure when live, and dead oils are injected into the core, and its comparison with previous experiments performed in water-wet systems.

The use of abbreviations for the gas dissolved in the crude oil, such as $100 \%$ methane, $75 \%$ methane, or $47 \%$ methane, refers to the percentage of the main component of the gas in solution. For example, when it is mentioned that the dissolved gas content is $75 \%$ methane, this refers to the fact that the gas in solution within the oil phase is a multi-component gas, which has $75 \%$ methane; and the remaining $25 \%$ is composed of other components ranging from $\mathrm{C}_{2}$ to $\mathrm{C}_{10}$, including $\mathrm{CO}_{2}$. It should be noted that the crude oil is $100 \%$ saturated with its respective solution gas. Figure 7 describes a qualitative approach to determine the wettability of rock from the pressure behaviour; this method was developed by the author, since as far as is known, a similar analysis had not been considered in the past. The graph presents the differential pressure behaviour for live oil injection in the six experiments presented in Table 1. The plotted information comes from laboratory data when live crude oil is injected into the core at experimental conditions, i.e. $140^{\circ} \mathrm{F}$, and $1200 \mathrm{psi}$.

Usually, these injection processes are conducted at different injection rates, whereby, after a stabilization in the differential pressure at a specific rate is obtained, the value is recorded, and graphed. It is expected, according to Darcy's law that this behaviour in the differential pressure at stabilized conditions will behave as a straight line. The chart shows the behaviour of the differential pressure when injecting live oil through the core, under two different scenarios of live oil composition. Each scenario, i.e. each graph, shows how these differentials behave when the core was not aged (continuous line), and when it was aged (dotted line). 
The objective of these graphs is to identify whether under the same conditions, in a specific pair of experiments, the differential pressure behaved the same, or different. In case it was different, the most plausible explanation is the ageing effect into the core, and therefore a representation of its wettability. In other words, the ageing process is successful, and therefore the core wettability goes from being water-wet to being non-water-wet.

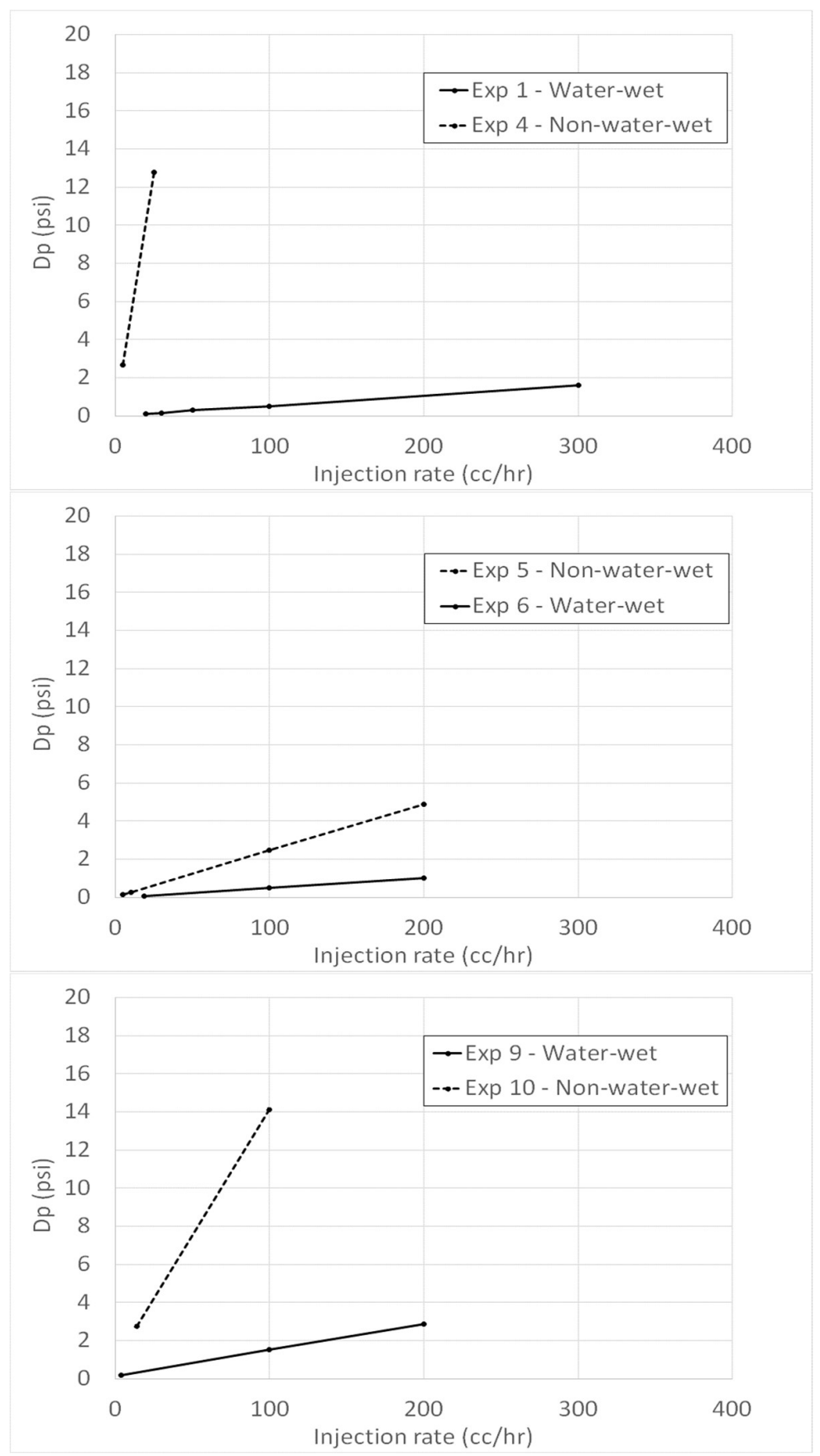

Figure 7. Differential pressure behaviour by using live oil at different injection rates. Top: heavier oil, and $100 \% \mathrm{CH}_{4}$. Middle: lighter oil, and a multi-component gas $75 \% \mathrm{CH}_{4}$. Bottom; lighter oil, and a multi-component gas $47 \% \mathrm{CH}_{4}$. 
The analysis of the graph concludes that, in fact, for each pair of experiments, the ageing process was successful, since there is a change between the slopes of the differential pressure behaviour at aged, and non-aged conditions. Additionally, it is consistently observed that the aged scenario will always have a higher differential pressure. The variability between the slopes is more evident in the nonwater-wet scenarios than in the water-wet scenario. This could be explained by the complexity of the oil phase used, which combined with the rock mineralogy, and the $\mathrm{CO}_{2}$ content would generate a response that is not completely clear. A similar response to the one presented in Figure 7 for live oils, was observed in dead oils; in other words, a greater slope is obtained for those aged systems in comparison to non-aged ones. As can be seen in the middle section of Figure 7, where the results of the experiments 5 and 6 are presented, the contrast between the aged, and non-aged system is not as strong as in the top, and bottom sections of the same figure. This is because the fluid used to age experiment 5 was different from the other two, i.e. experiments 4 and 10, which means that although the tendency of wettability does change, this change is not as drastic as in the other two experiments. This could be interpreted to mean that experiment 5 is not as wet to oil as experiments 4 and 10 , indicating a probable mix-wet system, qualitatively speaking.

\subsection{Determination of wettability. Permeability method.}

Keelan [19] proposed a methodology to determinate the rock wettability by using permeability values. Honarpour [1] et al. summarised Keelan's method, it consists by comparing the ratio of water permeability calculated at residual oil saturation with the oil permeability at connate water saturation. If the ratio is less than 0.3 , the sample is assumed to be water-wet, while a value near to one indicates that the sample is oil-wet. Any value between these two limits, can be considered as an indication of mixed wettability. Table 9, summarises the results obtained by the method described above for the determination of wettability in the core flooding experiments analysed.

Table 9. Determination of wettability by using the permeability method

\begin{tabular}{|l|c|l|}
\hline & $\frac{K w @ S o r}{K o @ S w c}$ & \multicolumn{1}{|c|}{ Wettability } \\
\hline Experiment 1 & 0,07 & Water-wet \\
\hline Experiment 4 & 0,99 & Oil-wet \\
\hline Experiment 5 & 0.31 & Mix-wet \\
\hline Experiment 6 & 0.26 & Water-wet \\
\hline Experiment 9 & 0,18 & Water-wet \\
\hline Experiment 10 & 0,90 & Oil-wet \\
\hline
\end{tabular}

The results obtained are consistent with what was expected. In other words, those experiments, where an ageing process was deliberately implemented, resulted in a strong oil-wet system. Regarding the 
experiments that did not have aging, a water wettability was obtained without any doubt. However, again experiment 5, where another fluid was used to age the core in order to obtain mixed wettability, the result of the relationship proposed by Keelan suggests that a mixed wettability system was in fact achieved as intended.

\subsection{Determination of wettability. Waterflood method.}

Numerous attempts to historically establish a single correlation based on conventional water injection behaviour, and wettability have failed [20]. However, under well controlled laboratory conditions, the results obtained from a conventional water injection process have been used to qualitatively establish the preferential wettability of the rock. It has been found that in strongly water-wet rocks, a large proportion of the oil is produced before the breakthrough, while very little additional oil is recovered after it [1]. Table 10 presents the determination of the wettability by using this method.

Table 10. Determination of wettability by using the waterflood method

\begin{tabular}{|l|c|c|l|}
\hline & $\begin{array}{c}\text { Oil recovery before } \\
\text { breakthrough }\end{array}$ & $\begin{array}{c}\text { Additional oil recovery } \\
\text { after breakthrough }\end{array}$ & \multicolumn{1}{|c|}{ Wettability } \\
\hline Exp 1 & $65,10 \%$ & $2,50 \%$ & Water-wet \\
\hline Exp 4 & $17,20 \%$ & $20,10 \%$ & Oil-wet \\
\hline Exp 5 & $43,10 \%$ & $3,30 \%$ & Mix-wet \\
\hline Exp 6 & $60,50 \%$ & $0.90 \%$ & Water-wet \\
\hline Exp 9 & $58,90 \%$ & $3,40 \%$ & Water-wet \\
\hline Exp 10 & $41,00 \%$ & $12,40 \%$ & Oil-wet \\
\hline
\end{tabular}

The results obtained maintain the consistency presented in the two previous sections, in other words, the experiments considered as water-wet are maintained in that manner; and this also applies to the experiments considered as oil-wet. For the mixed wettability experiment, i.e. experiment 5 , the results obtained by this method are also consistent; i.e. less oil recovery was obtained before breakthrough, indicating oil or mixed wettability; whereas oil recovery after breakthrough is low, which could indicate a mixed wettability system by combining it with the low pre-breakthrough oil recovery factor. Thus, it is possible to conclude that the ageing process was effective, as it was designed, and the wettability corresponds to what was expected for the four experiments. The above was corroborated by three different methods, of which the first one, as far as the author is aware, was developed by himself.

\section{Experimental results, and discussions}

\subsection{Impact of wettability in general}

Six experiments were conducted to analyse the effect of the rock wettability on the oil recovery, and on the pressure trends. The experiments were grouped in pairs, i.e., experiments 1 and 4 , experiments 5 and 6 , and experiments 9 and 10 . This grouping was made considering exclusively the change due 
to the wettability of the rock; all of the other experimental variables were kept the same. Figure 8 presents the results of experiments 5 and 6 .

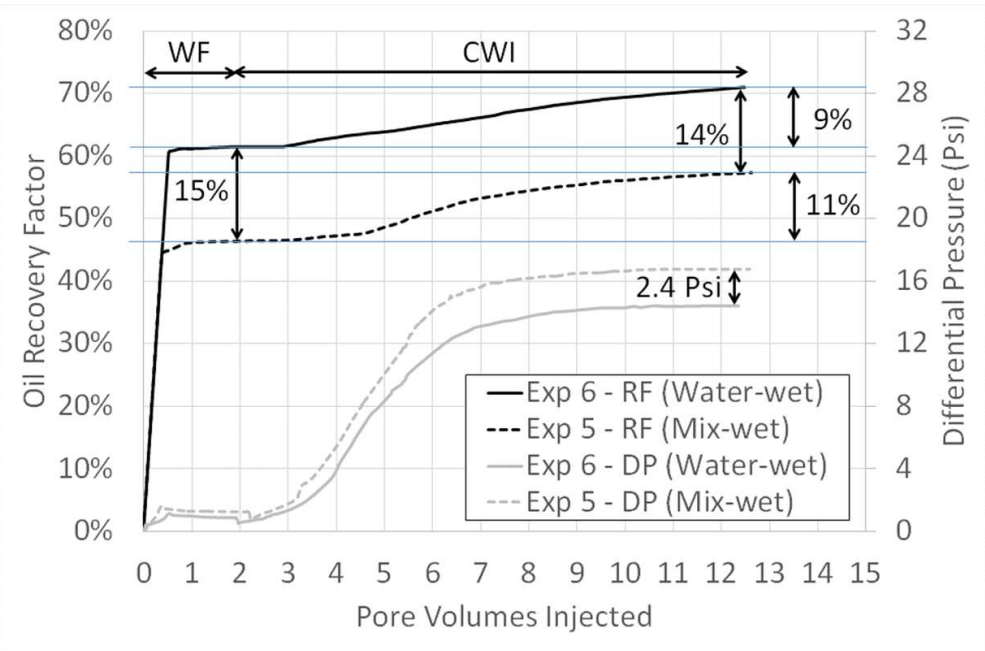

Figure 8. Experimental results for experiments 5 and 6

The oil recovery factor (RF), and the differential pressure (DP) for both conventional waterflooding (WF), and the injection of carbonated water are plotted in the figure. From the experimental results, it was inferred that the wettability of rock has an important effect on the differential pressure behaviour. A mix-wet rock causes a greater differential pressure response compared to a water-wet rock, because an additional effort is required to mobilize the fluid that predominantly is wetting the rock. This behaviour is more evident in the stage in which tertiary carbonated water is injected because the separation between the curves is much greater due to the formation of a new gas phase in the system by the interaction between the $\mathrm{CO}_{2}$ and the oil phase.

Before the injection of carbonated water begins, the residual oil that remains in the system is adhered to the rock grains; freeing this residual oil will require additional energy which would increase the pressure. It is assumed that the formation of the new gas phase defined by Sohrabi et al. [8] is the main responsible for the significant increase in the differential pressure that occurs when the injection of carbonated water is initiated. The formation of the new gas phase is caused by the mass transfer of $\mathrm{CO}_{2}$, from the carbonated water phase to the oil phase, which occurs in a one-way flow.

The $\mathrm{CO}_{2}$ that is transferred to the oil phase begins to expel the lighter components in this phase, and, simultaneously, the nucleation of a new gas phase within the oil is initiated. This new gas phase causes a remobilization of the isolated oil ganglions, promoting their joining, and subsequent production. Because $\mathrm{CO}_{2}$ is more soluble in the oil phase than in aqueous phase, various pore volumes of $\mathrm{CW}$ will have to be injected to fully saturate the oil phase with $\mathrm{CO}_{2}$, thus the differential pressure will increase until a significant degree of saturation is obtained; for this case, stabilization of the a differential pressure was reached after injecting about seven pore volumes of carbonated water.

The results of the experiments presented show that there was a significant increase in the differential pressure when carbonated water was injected instead of flooding the core with brine. A similar observation was never reported in the numerous field projects that were conducted in the 1950's and 1960 's (calcareous rocks), nor in the previous carbonated water injection experiments. It is intuitive that the cause of these results is the scale of the current experiments (whole core), so it is 
recommended that some of these experiments be repeated in a longer core, so the results could be compared.

The experimental results also showed that in water-wet system was obtained a higher oil recovery factor if the secondary, and tertiary stages are combined. However, this is mainly due to the results of the waterflooding (secondary) stage, in which a $15 \%$ difference was reached between the waterwet system, and the mix-wet system. The results additionally showed that, in the tertiary stage, that is associated with the injection of carbonated water, the mix-wet system recovers more oil; an additional $11 \%$ oil recovery factor was achieved in the mix-wet system by carbonated water injection, while only $9 \%$ was recovered in a water-wet system. This is because after flooding with water the core, there is a greater amount of residual oil ( $\left.\mathrm{S}_{\mathrm{or}}\right)$ in the mix-wet system, so there is a greater volume of hydrocarbons where the new gas phase will be formed. Thus, all mix-wet systems should have oil recoveries higher than a water-wet system during carbonated water injection in a tertiary scenario under the same experimental conditions. This means that the injection of carbonated water could be an excellent alternative for increasing the production of oil in mix-wet reservoirs.

Based on the analyses performed by Sohrabi et at. [8] on micro models, it was concluded that the injection of carbonated water causes the wettability of the system to be changed to more water-wet scenario. It could be inferred from Figure 8 that this effect is apparently occurring in the oil recovery factor curve. In that curve, although the difference in the oil recovery factor after waterflooding was $15 \%$, it was reduced to $14 \%$ after carbonated water injection. This means that, at the end of the injection of carbonated water, the recovery factor curve in the oil-wet system is one percentage point closer to the water wetting system. It is possible that this phenomenon is more evident in those oilwet systems.

Figure 9 presents the oil recovery factor, and differential pressure results for experiments 9 and 10 . Contrary to the previous pair of experiments, in this new pair, the content of dissolved methane mole fraction in the live oil decreased from $20 \%$ to $16 \%$ (see Figure 4); in other words, the methane content of the gas has decreased from $75 \%$ to $47 \%$; the other experimental variables remained the same. Again, the experimental results showed that the differential pressure is greater in an oil-wet system than it is in its water-wet counterpart. The results also, consistently show the rapid increase in the pressure after the secondary waterflooding, and this increase is associated with the formation of the new gas phase when the injection of carbonated water is initiated.

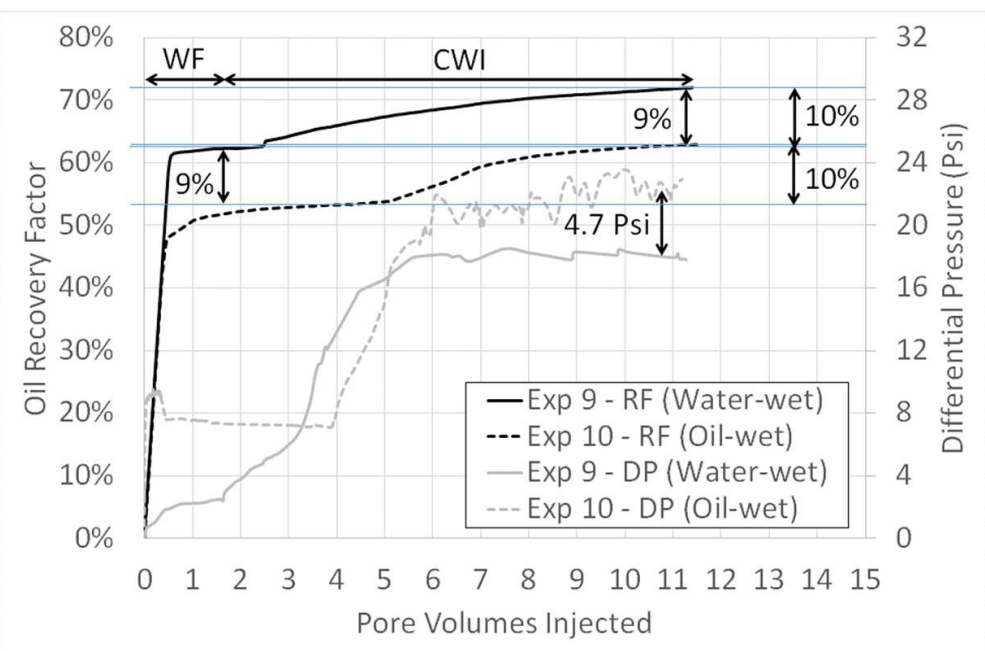

Figure 9. Experimental results for experiments 9 and 10 
Although in general terms the results presented in Figure 8, and Figure 9 have many similarities, it is necessary to investigate more deeply to identify any small difference that may exist. Even though the same experimental equipment were used, i.e., transducers, transfer lines, and generally the same apparatus, there was a difference between the values of the differential pressure, and this difference occurred in both the mix/oil-wet, and water-wet systems. It can be concluded that in the experiments with a lower percentage of dissolved methane (experiments 9 and 10), the values of the differential pressure were higher.

Theoretically, by Darcy's law, because of the lower viscosities in experiments 9 and 10 (see Table 5), a lower differential pressure should be obtained, but the results indicated just the opposite. This means that the reduction in viscosity was insufficient to exceed some other effect that was occurring in the system. This other effect must be the formation of the new gas phase, which has been shown to be the main production mechanism in the injection of carbonated water when live oil is used. Therefore, by Darcy's law, the formation of this new gaseous phase must affect mainly the effective/relative permeability, and it must do so in a significant proportion. This was expected because the system changes from a two-phase system to a three-phase system when the new gaseous phase is formed.

Another finding from the experimental results was that the formation of the new gas phase is not determined directly by the methane content. Since the differential pressure increases in both waterwet, and oil-wet systems as the methane content decreases, it is apparent that the growth of the new gas phase is governed by light components other than methane.

A comparison of Figure 8, and Figure 9 also shows that, at the end of the carbonated water injection for those experiments with a higher methane content, the pressure difference between the water-wet, and the mix-wet system was $2.4 \mathrm{psi}$, whereas, for the experiments with lower methane content, the pressure difference between the water-wet, and the oil-wet system was $4.7 \mathrm{psi}$. This indicates that the wettability, as represented by the differential pressure behaviour, was affected inversely by the content of the methane dissolved in the live oil.

Based on the analysis of the differential pressure behaviour of the mix/oil-wet systems, it was concluded that the methane content impacts these systems to a significant extent. For example, the differential pressure was $22.5 \mathrm{psi}$ at the end of the CWI when the methane content was lower, but it was $16.8 \mathrm{psi}$ in the system that had the higher content of methane, and the difference between them was significant, i.e., 5.7 psi. However, if the same comparison were made for the water-wet systems, the difference between them is just 3.5 psi. Stabilization of the differential pressure occurred after injecting about 6 pore volumes of carbonated water for those systems that had lower methane contents. This means that the lower the methane content is, the faster stabilization of the differential pressure for carbonated water injection will be reached.

The oil recovery factor counting waterflooding, and carbonated water injection presented in Figure 9 indicates again that water-wet systems have higher oil recoveries. However, it also indicates that the reduction in the content of methane reduces the delta between the curves of different wettability to 9 $\%$, instead of $14 \%$. This indicates that the oil-wet curve is moving closer to the water-wet curve and, therefore, there is greater effectiveness in the formation of the new gas phase in the oil-wet experiment. Again, it is important to emphasize that, for both types of wettability, the injection of carbonated water produced a very favourable result, i.e., a $10 \%$ incremental oil recovery factor.

Figure 10 presents the oil recovery factor, and differential pressure results for experiments 1 and 4 . For this pair of experiments the gas selected to be used in combination with the heavier dead oil was $100 \%$ methane; however after mixing this gas with the dead oil, the percentage of methane in the recombined oil is $23 \%$, as presented in previous sections (see Figure 4). 


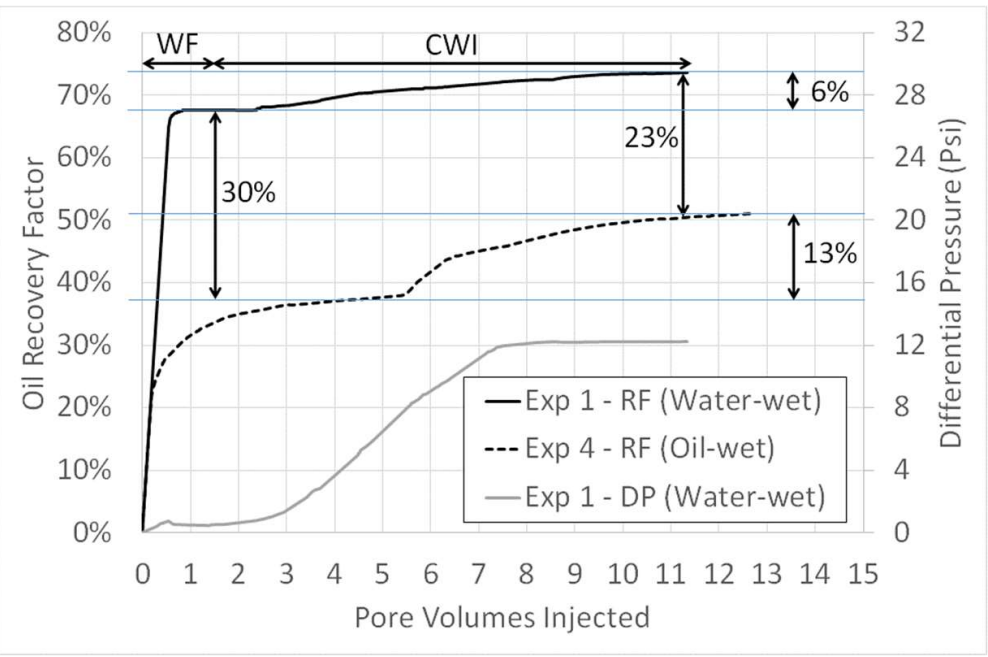

Figure 10. Experimental results for experiments 1 and 4

For experiment 4 , there were reported some difficulties with the pressure transducers during its performance and therefore, unfortunately, the pressure values were not properly recorded. However, it was considered that the production performance is sufficiently valid by itself to be integrated into this analysis. The crude oil used in this pair of experiments is different from that used in experiments 5 and 6, and in experiments 9 and 10; in other words, in this pair the heavier oil was used, while in the other 4 experiments the lighter oil was used.

The results presented in Figure 8, and Figure 9 indicate that there was an inverse relationship between the amount of methane dissolved in the oil and the differential pressure, i.e., as the content of methane dissolved in the oil increased, the differential pressure decreased. This finding was confirmed by the pressure behaviour that was observed in experiment 1 (water-wet), in which the differential pressure at the end of the carbonates water injection was 12.3 psi with a methane content of $23 \%$ in the recombined oil. The observations also confirmed that the behaviour of the differential pressure that occurred when the carbonated water was injected is possible due to the formation of the new gas phase.

Regarding the production behaviour presented in Figure 10, again, the experimental results showed that a water-wet system has a higher recovery factor when both waterflooding, and carbonated water are considered together. However, it also was proved that the methane content affected the mix/oilwet systems to a greater extent. For example, in the system with the highest methane content (in oilwet), the oil recovery factor was the lowest. The results of these experiments also showed that the injection of carbonated water into an oil-wet system was very successful, especially when there was a high methane content. Figure 10 shows that the difference between the oil recovery factor curves (with different wettabilities) went from $30 \%$ at the end of the waterflooding to $23 \%$ at the end of the carbonated water injection. In other words, due to the CWI, the recovery in an oil-wet system approached the water-wet system curve by $7 \%$ due to the high methane content in the system.

\subsection{Impact of wettability on tertiary carbonated water injection}

Figure 11 summarizes the incremental oil recovery factor associated with the injection of carbonated water for the six experiments performed when seven pore volumes were injected. The value of seven pore volumes was chosen because, at that point, the differential pressure was stabilized, and most of the incremental oil had been produced. The white bars show the results of the experiments performed 
in mix/oil-wet systems, and the black bars show the results of the water-wet experiments. The two experiments on the left side has a methane content of $20 \%$, whereas the two experiments in the middle, and the two experiments on the right side have methane content of $16 \%$ and $23 \%$, respectively. This plot clearly indicates that better incremental recovery was obtained in the mix/oilwet systems in which the injection of carbonated water was performed in a tertiary injection scenario. This is due to the fact that in these systems after waterflooding, a greater quantity of residual oil remained in the rock, which allowed a greater formation of the new gaseous phase and, therefore, the production of a greater amount of oil. The impact that the methane dissolved in the live crude oil had on the production behaviour also was observed, i.e., the higher the methane content, the higher the differences between the curves of the different wettabilities; in our experiments, these differences varied between $1.1 \%$ and $8.3 \%$.

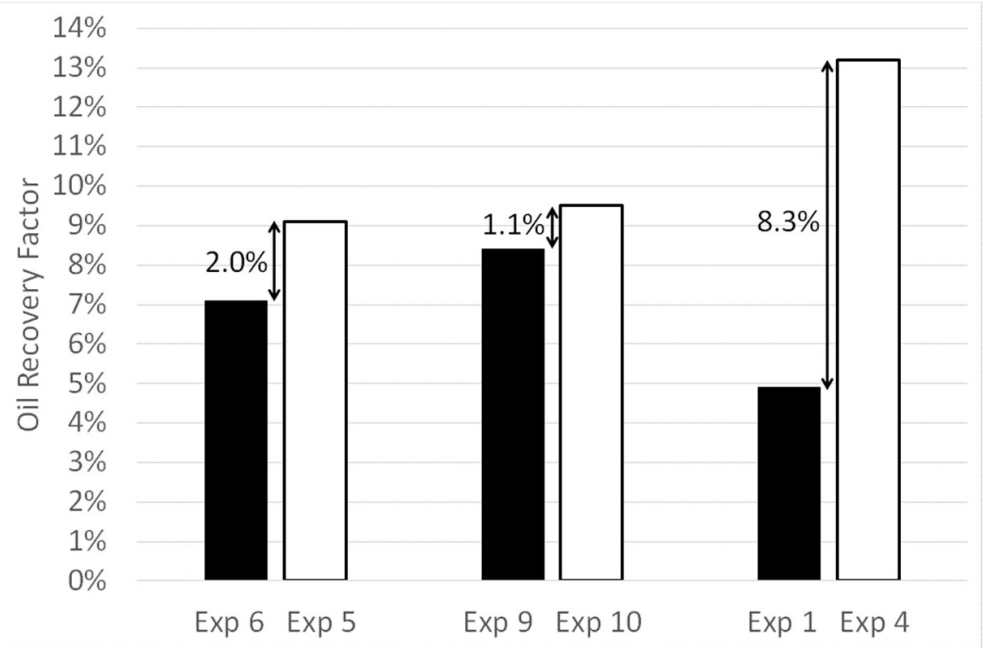

Figure 11. Oil recovery factor for the tertiary carbonated water injection scenario calculated at 7 pore volumes injected of CWI

The incremental oil recovery factor associated with the tertiary injection of carbonated water varied depending on the wettability of the rock, and the content of dissolved methane. For example, in a water-wet system, better recovery will be obtained when the methane content is low because the oil has more light components other than methane. These other components allow a higher growth of the new gas phase and, therefore, a greater amount of oil is produced. However, in a mix/oil-wet system, two variables affect the quantity of oil that is recovered during the tertiary injection of carbonated water. The first variable is the quantity of crude oil that was produced during the secondary waterflooding; generally, the amount of oil produced in the secondary stage has an inverse relationship with the amount of oil produced in the tertiary stage. The second variable is the methane content; as stated above, the methane content has an inverse relationship with the growth of the new gas phase, so there will be a higher production of oil.

Figure 12 shows the differential pressures associated with the injection of tertiary carbonated water for the five experiments that were performed when seven pore volumes were injected; the same nomenclature used in Figure 11 is used in Figure 12. In both the water-wet, and the mix/oil-wet systems, there is a correspondence between differential pressure and oil recovery, i.e., the experiments that have higher differential pressures also have higher tertiary incremental oil recoveries. Therefore, 
the same reasoning of the consequences of the formation of the new gas phase, and the methane content realized for the behaviour of the oil recovery factor is valid for the differential pressure.

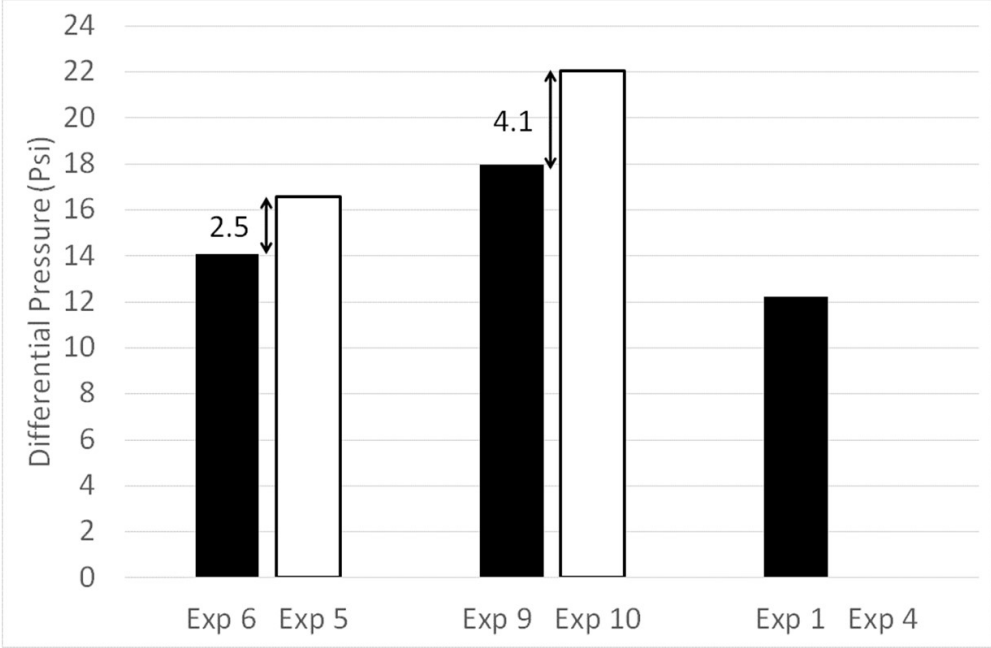

Figure 12. Differential pressure for the tertiary carbonated water injection scenario calculated at 7 pore volumes injected of CWI

\subsection{Impact of wettability on oil recovery efficiency}

Figure 13 shows the approximate number of pore volumes of carbonated water required to reach $75 \%$ of the incremental production recovered in the tertiary scenario for the water-wet experiments. The plot presents that $75 \%$ of the normalized incremental production was reached after six, or seven pore volumes (depending on the experiment) had been injected. This variation of six, or seven pore volumes depends exclusively on the methane content of the experiment that is being evaluated. The lower the methane content, the higher the recovery factor becomes. As explained earlier, this is due to the effect that the methane content has on the formation of the new gaseous phase, i.e., the less methane in the system, the greater the growth of the new gaseous phase will be and, therefore, the greater the incremental oil production will be.

Figure 13 also shows that the methane content affects the incremental oil production more strongly during the injection of the initial pore volumes. For example, for the experiment in which the methane content in the recombined oil was $20 \%$ (experiment 6 ), only $16 \%$ of the total oil incremental production was recovered after injecting two pore volumes; however, for the experiment in which the methane content was $16 \%$ (experiment 9), $32 \%$ of the incremental oil production was recovered after injecting two pore volumes. These observations clearly indicate that the methane content affects the efficiency, or the speed of the recovery of the incremental oil in a tertiary, carbonated-water injection process.

Figure 14 presents the normalised percentage of incremental oil production recovered during the tertiary injection of carbonated water for mix/oil-wet experiments. The figure shows that the experiment with the lowest methane content achieves $75 \%$ of the incremental oil production at the fourth pore volume that was injected, while the experiment with the highest methane content achieved $75 \%$ of the incremental oil production after six pore volumes were injected. 


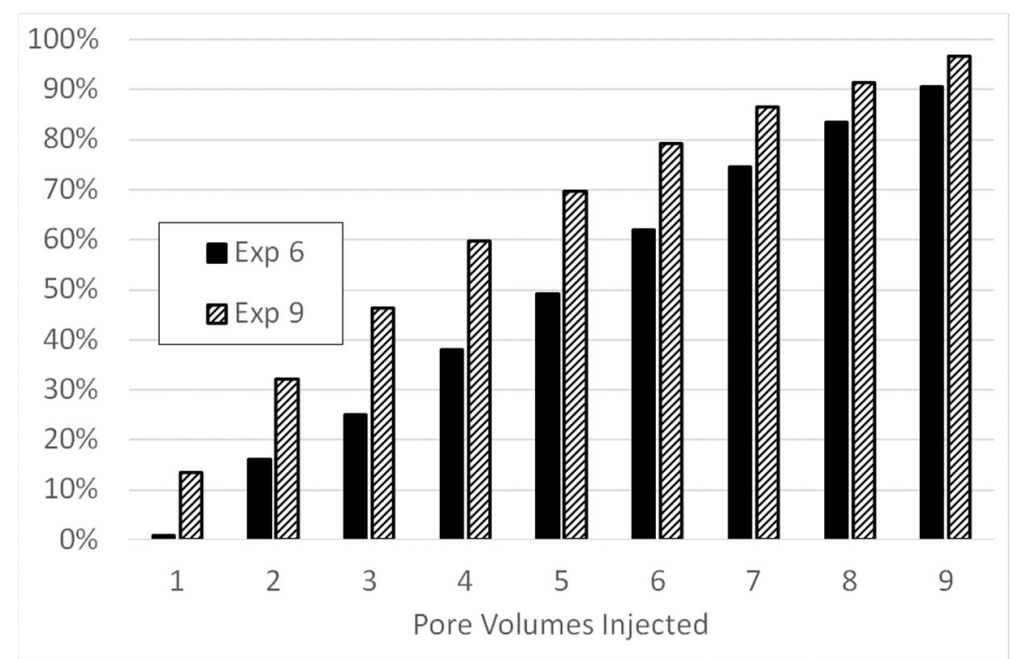

Figure 13. Normalised percentage of incremental oil production recovered in the tertiary CWI for water-wet experiments

Again, the experiment with lower methane content was more efficient, i.e. it reached $75 \%$ of the incremental production earlier. Thus, irrespective of the wettability of the rock, the methane content will govern the speed, or efficiency of production in a tertiary carbonated water injection process. As in Figure 13, the graph in Figure 14 presents the effect of the methane content on the initial volumes injected much more evident. For example, in the experiment with a lower methane content (experiment 10) $34 \%$ of the incremental oil production was recovered after injecting two porous volumes, but, for the experiment with a higher methane content (experiment 5), the two porous volumes injected with carbonated water recovered only $9 \%$ of the total incremental oil production associated with the injection of carbonated water.

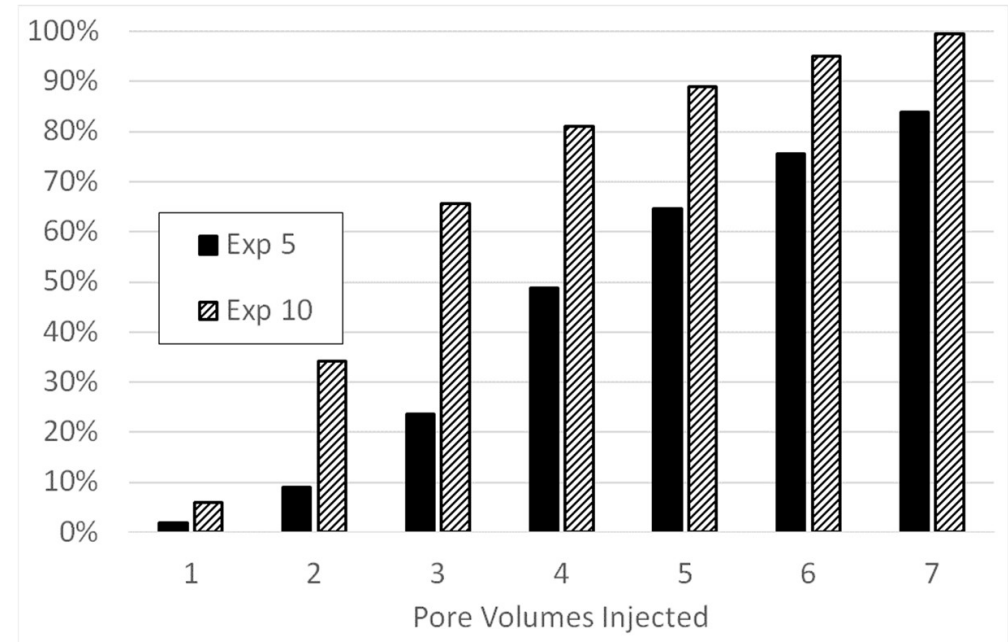

Figure 14. Normalised percentage of incremental oil production recovered in the tertiary CWI for mix/oil-wet experiments 
However, when Figure 13, and Figure 14 are compared, i.e., if the wettability effect on the rock is compared, it is possible to conclude that a mix/oil-wet rock is more efficient in a tertiary carbonated water injection process because the incremental oil recovery will occur in a shorter amount of time. The main reason for this, is that there is more oil adhering to the grains of the rock after the secondary waterflooding into a mix/oil-wet rock. This causes a lower relative permeability of the oil compared to a water-wet rock. Thus, when the tertiary injection of carbonated water is initiated, more oil is available within the rock to be affected by the mass transfer of $\mathrm{CO}_{2}$ from the brine to the oil. As a result, there will be a greater formation of the new gas phase within the system and, therefore, a greater production of incremental oil.

\subsection{Impact of wettability on new gas phase}

The importance of having a high saturation of the new gas phase has been discussed throughout the document. In his research, Al Mesmari et al. [21] defined the saturation of the new gas phase associated to the injection of carbonated water as shown in equation 1 .

$$
S_{o}^{C W I}+S_{N P}^{C W I}=S_{\text {orw }}
$$

where $S_{o}{ }^{C W I}$ is the oil saturation in the core during tertiary carbonated water injection; $S_{N P}{ }^{C W I}$ is the saturation of the new gas phase that forms during carbonated water injection; and $S_{\text {orw }}$ is the residual oil saturation after secondary waterflooding. The new gas phase saturation was calculated according to equation 1 for all the experiments.

Based on the above results, and their analysis, there is a relationship between the saturation of the new gas phase, and the incremental oil recovery factor associated with tertiary injection of carbonated water. Figure 15, Figure 16, and Figure 17 present the relationships between the variables mentioned above for each pair of the performed experiments.

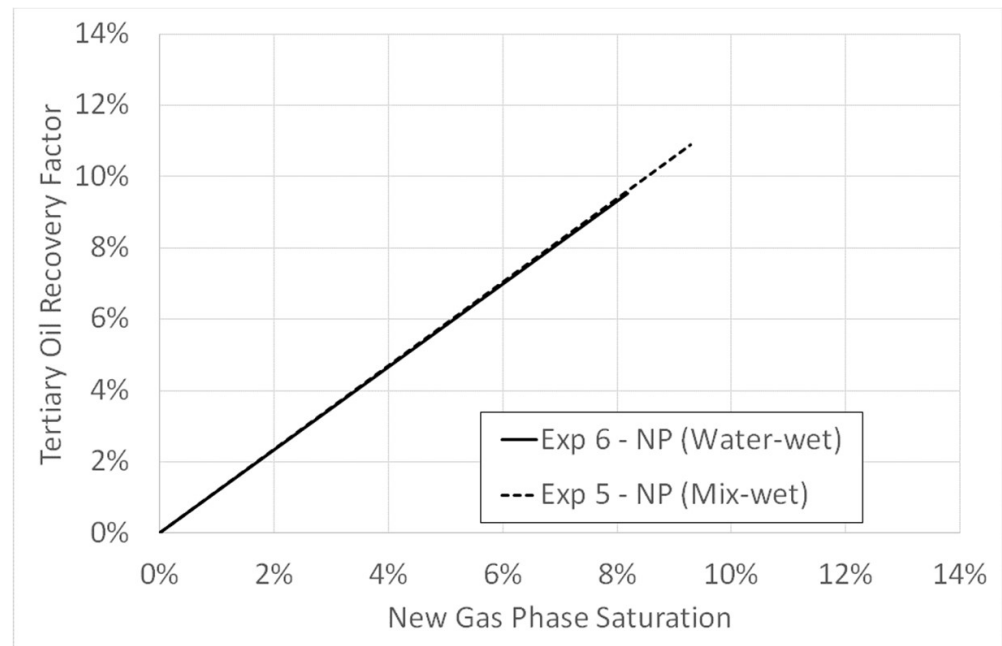

Figure 15. New gas phase saturation versus tertiary oil recovery for experiments with $20 \%$ of methane content in the recombined oil 
In each of these figures, it is consistently shown that there is a linear relationship between the saturation of the new gas phase, and the tertiary oil recovery factor associated to the carbonated water injection. Graphically, it can be observed that the slopes between each curve are quite similar irrespective of the methane content, dead oil composition, or wettability of the rock. All charts are presented at the same scale to facilitate their analysis.

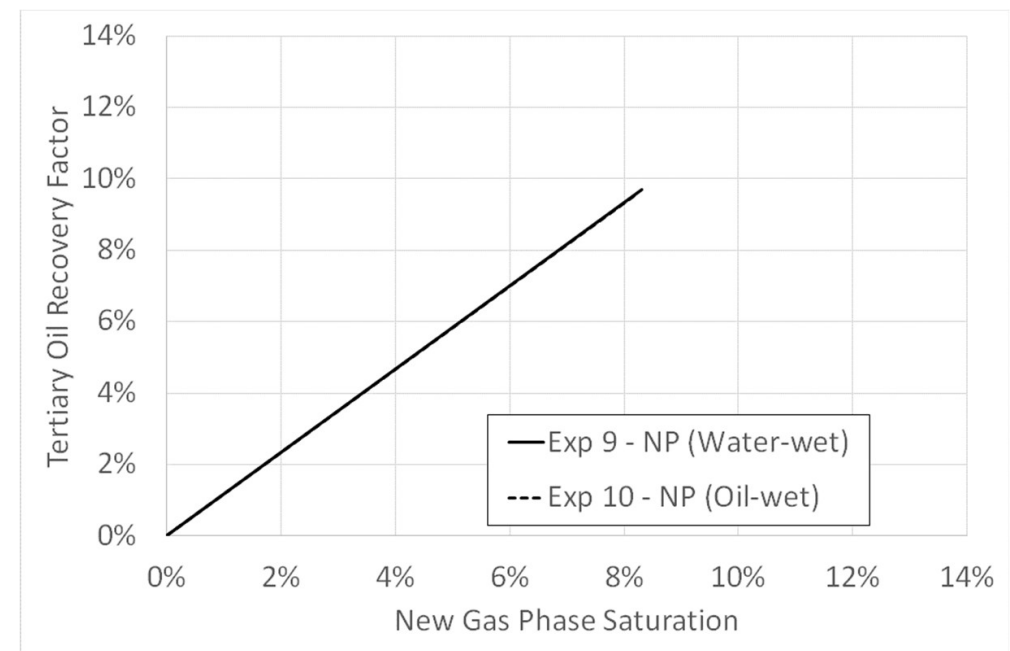

Figure 16. New gas phase saturation versus tertiary oil recovery for experiments with $16 \%$ methane content in the recombined oil

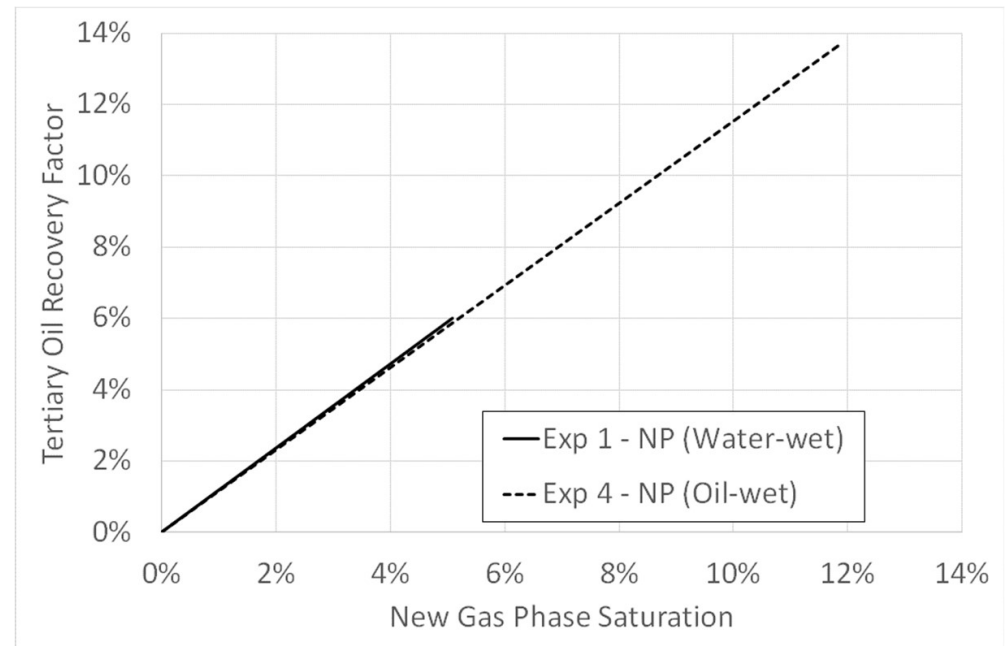

Figure 17. New gas phase saturation versus tertiary oil recovery for experiments with $23 \%$ methane content in the recombined oil

Table 11 shows the values that correspond to each of the slopes, and equations of the curves represented in Figure 15, Figure 16, and Figure 17. 
Table 11. Slope and equation comparisons

\begin{tabular}{|c|c|l|}
\hline Experiment & Slope & \multicolumn{1}{|c|}{ Equation } \\
\hline 6 & 1.1619 & $\mathrm{Y}=1.1619 * \mathrm{X}$ \\
\hline 5 & 1.1744 & $\mathrm{Y}=1.1744 * \mathrm{X}+6 \mathrm{E}-17$ \\
\hline 9 & 1.1678 & $\mathrm{Y}=1.1678 * \mathrm{X}-2 \mathrm{E}-16$ \\
\hline 10 & 1.1670 & $\mathrm{Y}=1.1670 * \mathrm{X}+1 \mathrm{E}-16$ \\
\hline 1 & 1.1824 & $\mathrm{Y}=1.1824 * \mathrm{X}-1 \mathrm{E}-17$ \\
\hline 4 & 1.1538 & $\mathrm{Y}=1.1538 * \mathrm{X}+4 \mathrm{E}-17$ \\
\hline
\end{tabular}

As can be seen, the slopes of each straight line have similar values. These values were subjected to a statistical analysis, the mean is calculated as 1.1679 , and the standard deviation is 0.00988 . Therefore, a valid approximation for the calculation of the tertiary oil recovery factor, associated to the carbonated water injection would be:

$$
T_{O R F}=1.1679 * S_{N P}{ }^{C W I}
$$

where $T_{O R F}$ is the tertiary oil recovery factor due to the carbonated water injection.

Equation 2 can be used to calculate the effectiveness of a carbonated water injection process. It should be evaluated for experiments to identify its universality.

\subsection{A comparison of the impact of wettability and methane content}

Although the wettability of the rock influences the differential pressure behaviour of the tertiary carbonated water injection, it is the content of the methane in the crude that has the greatest relevance in the behaviour of the pressure. The results plotted in Figure 18, and Figure 19 are proof of this conclusion.

Figure 18 shows that the differential pressure changes due to the methane content are greater than the differential pressure changes due to wettability. While Figure 19 shows that the differential pressure changes due to the methane content in a mix/oil-wet system is greater than the differential pressure changes due the methane content in a water-wet system. 


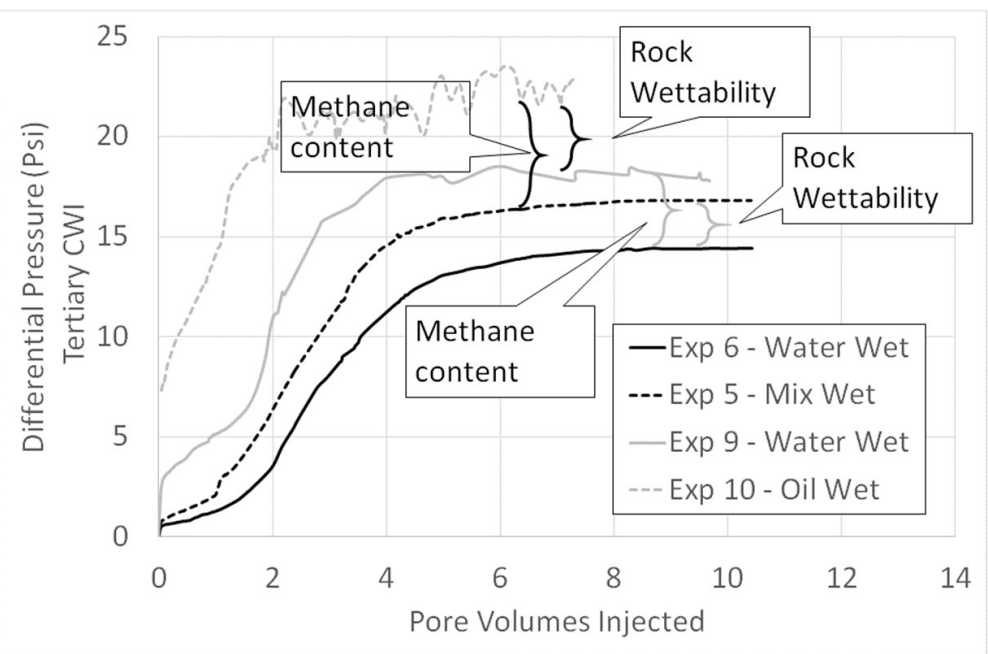

Figure 18. Effect of the methane content, and rock wettability on the tertiary differential pressure

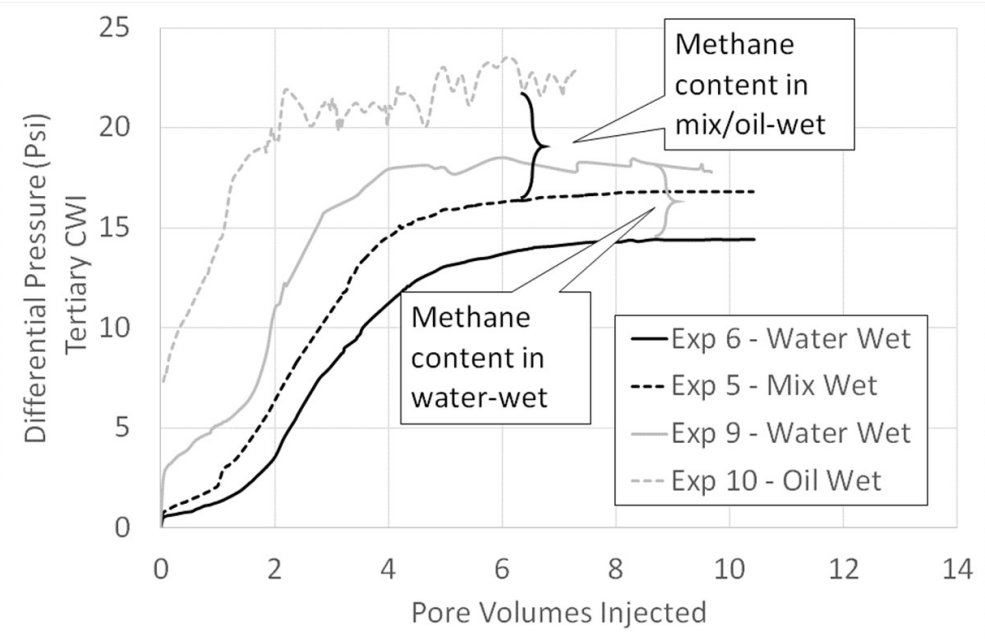

Figure 19. Effect of the methane content in mix/oil-wet, and water-wet systems on the differential pressure

\subsection{A correlation between the Keelan ratio and the incremental tertiary oil recovery factor}

Figure 20, presents the trend obtained when the Keelan's ratio presented in Table 9 is associated, together with the incremental oil recovery factor from carbonate water injection. Three zones can be seen, the first being the water-wet zone, the second being the mixed-wet zone, and the third being the oil-wet zone.

The graph shows a slight trend between the Keelan ratio, and the tertiary incremental recovery factor obtained. The lower the ratio, i.e. the more water-wet the system is, the lower the recovery to be achieved by the carbonated water; however, as this ratio increases, i.e. the more oil-wet the system becomes, the more oil will be recovered. In addition, it would be very useful to perform this type of analysis using various values of the Keelan ratio to try to obtain a mathematical correlation between this ratio, and the incremental factor of oil recovery associated with tertiary injection of carbonated 
water. Finally, the visualised results of this graph would then confirm that the wettability analysis performed in a previous section was completely successful.

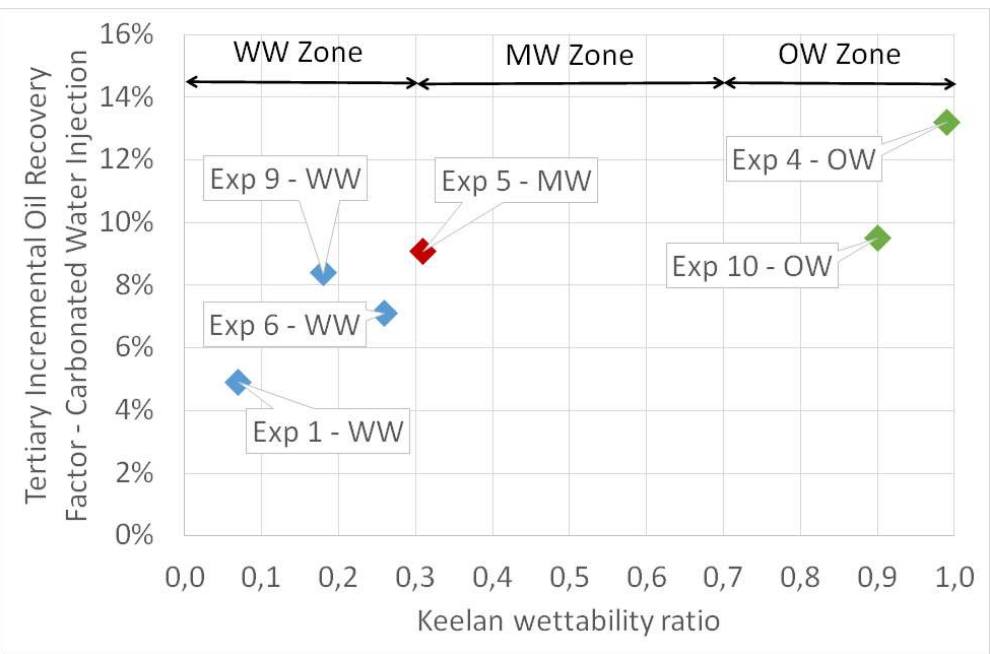

Figure 20. Relationship between Keelan ratio, and tertiary incremental oil recovery factor associated to carbonates water injection. Abbreviations mean WW (water-wet), MW (mix-wet), and OW (oil-wet)

Regarding the change in wettability associated with the injection of carbonated water, there is slight evidence of the occurrence of this phenomenon, or more precisely, of the impact of this phenomenon on the experiments performed. As previously explained, when there is a reduction in the gap between the recovery factor of water-wet systems, and mix/oil-wet systems in the tertiary stage of carbonated water injection, this reduction could be associated with the change in wettability, considering that the only variable that changes is the wettability of the system. Table 12 presents the relationship of these gaps. For example, for the first pair of experiments, the difference between the oil recovery factor after the conventional waterflooding was $30.3 \%$, but after the injection of carbonated water this difference became $22.5 \%$, in other words, implicitly the change in the wettability of the rock, associated with various factors such as the formation of the new gas phase, had an impact of $7.8 \%$ when the two experiments are compared. However, as already mentioned, there are other factors more predominant to the change of the rock wettability in the response of the oil recovery factor of the carbonated water injection, such as the formation of the new gas phase and the composition of the recombined crude.

Table 12. implicit impact on oil recovery associated with the change in wettability due to tertiary injection of carbonated water. EUR (Estimated ultimate recovery)

\begin{tabular}{|c|c|c|c|c|c|}
\hline & EUR@WF & GAP (1) & EUR@CWI & GAP (2) & $(1)-(2)$ \\
\hline Exp 1 & $67,60 \%$ & \multirow{2}{*}{$30,30 \%$} & $73,60 \%$ & \multirow{2}{*}{$22,50 \%$} & \multirow{2}{*}{$7,80 \%$} \\
\hline $\operatorname{Exp} 4$ & $37,30 \%$ & & $51,10 \%$ & & \\
\hline $\operatorname{Exp} 6$ & $61,40 \%$ & \multirow{2}{*}{$15,00 \%$} & $71,00 \%$ & \multirow{2}{*}{$13,70 \%$} & \multirow{2}{*}{$1,30 \%$} \\
\hline $\operatorname{Exp} 5$ & $46,40 \%$ & & $57,30 \%$ & & \\
\hline
\end{tabular}




\section{Conclusions}

A new series of high pressure, and high temperature coreflood experiments were performed to comprehend the role of rock wettability on the incremental oil recovery factor, and differential pressure behaviour. Throughout this research, different techniques were also evaluated to corroborate the type of wettability present in the rock, one of which is considered by the author to be completely novel. In addition, a new equation was also determined by the author to calculate the incremental oil recovery factor as a function of the saturation of the new gas phase. Based on the analysis of this investigation, the following conclusions were made:

i. $\quad$ Rock wettability plays an important role on the differential pressure behaviour for both waterflooding, and carbonated water injection. A mix/oil-wet rock causes a greater differential pressure response.

ii. A much higher differential pressure is obtained when carbonated water injection is started. This is assumed to be due to the formation of the new gas phase.

iii. A greater oil recovery factor is obtained in a water-wet system when both secondary waterflooding, and tertiary CWI oil recovery are summed. However, when only tertiary injection of carbonated water is analysed, a higher oil recovery is obtained in mix/oil-wet systems. The new gas phase formation is facilitated in mix/oil-wet systems.

iv. The methane content dissolved in live oil plays the main role for oil recovery, and differential pressure behaviour in a carbonated water injection process. It is inversely related to the pressure behaviour, and oil recovery. This occurs because a low methane content allows a higher formation of the new gas phase, and therefore a higher production of oil; however, the differential pressure increases at the same time.

v. Viscosity reduction due to $\mathrm{CO}_{2}$ mass transfer has a smaller effect in oil recovery, and differential pressure than the effect caused by the formation of a new gas phase.

vi. Regardless of the wettability of the rock, the speed at which the incremental oil is obtained is inversely related to the methane content, i.e., the mechanism is more efficient. The methane content affects the efficiency, or recovery velocity of the incremental oil in a tertiary carbonated water injection process.

vii. In the experiments that were conducted, the author calculated a novel linear relationship between new gas phase saturation, and tertiary oil recovery. This relationship is almost constant irrespective of the oil, and gas compositions and the wettability of the rock. This approach would allow the calculation of the additional tertiary oil recovery potential by the injection of carbonated water, based only on the saturation behaviour of the new gas phase; therefore the new objective of this recovery method would be to maximise the formation of this new phase.

viii. Although at laboratory scale there are different methods to determine the wettability of a rock, sometimes it is not possible to perform such measurements. Therefore, the author proposes a novel method that identifies trends in wettability, or better, compares trends based on Darcy's equation. This method was applied to the experiments conducted in this research, and its results were corroborated by other approaches available in the industry.

ix. Based on the results, it is possible to infer that by using a whole core the wettability change effect associated with the injection of carbonated water is not so preponderant, on the contrary, it could be more affected by the methane content in the system. The experiments conducted prior to this research had been focused on micro-models, and 1 to 2 inch diameter core evaluations, where the analysis was restricted to pore level or small scale behaviour, systems in which the impact of pore level wettability change is much greater. 


\section{Acknowledges}

The study was conducted in the Centre for Enhanced Oil Recovery (EOR) and CO2 Solutions of the Institute of Petroleum Engineering at Heriot-Watt University under the supervision of Prof. M. Sohrabi. The core flood experiments were conducted by Mr. Jaime Castaneda and supervised by Dr. Amir Farzaneh. The programme was equally supported by: The UK Department of Energy and Climate Change (DECC), Petrobras, Total Exploration and Production, ADCO, BG Group, and Galp Energia which are gratefully acknowledged.

\section{References}

[1] M. Honarpour, L. Koederitz, and A. H. Harvey, Relative permeability of petroleum reservoirs. 1986.

[2] W. G. Anderson, "Wettability Literature Survey- Part 2: Wettability Measurement," J. Pet. Technol., vol. November, pp. 1246-1262, 1986.

[3] H. Goda and P. Behrenbruch, "Wettability Quantification - Prediction of Wettability for Australian Formations," Int. Pet. Technol. Conf., 2012.

[4] J. E. Bobek, C. C. Mattax, and M. O. Denekas, "Reservoir Rock Wettability-Its Significance and Evaluation," Pet. Trans. AIME, vol. 213, pp. 155-160, 1958.

[5] W. G. Anderson, "Wettability Literature Survey - Part 4: Effects of Wettability on Capillary Pressure," J. Pet. Technol., no. October, pp. 1283-1300, 1987.

[6] W. G. Anderson, "Wettability Literature Survey - Part 5: The Effects of Wettability on Relative Permeability," J. Pet. Technol., no. November, pp. 1453-1468, 1987.

[7] W. G. Anderson, "Wettability Literature Survey - Part 6: the Effects of Wettability on Waterflooding.," J. Pet. Technol., no. December, pp. 1605-1622, 1987, doi: 10.1016/01489062(88)91583-5.

[8] M. Sohrabi, A. Emadi, S. A. Farzaneh, and S. Ireland, "A Thorough Investigation of Mechanisms of Enhanced Oil Recovery by Carbonated Water Injection," SPE Annu. Tech. Conf. Exhib., pp. 1-33, 2015, doi: 10.2118/175159-MS.

[9] M. Seyyedi, "Enhanced Oil Recovery by Carbonated ( CO 2 - Enriched ) Water Injection," Heriot Watt University, 2016.

[10] Y. Dong, B. Dindoruk, C. Ishizawa, E. Lewis, and T. Kubicek, "An experimental investigation of carbonated water flooding," SPE Annu. Tech. Conf. Exhib., pp. 1-16, 2011, doi: 10.2118/145380-MS.

[11] M. F. Mat Ali, R. Junin, N. H. Aziz, and A. Salleh, "Carbonated Water Injection for Recovery of Oil and Wettability Analysis," Appl. Mech. Mater., vol. 695, no. January, pp. 499-502, 2015, doi: 10.4028/http.

[12] M. Seyyedi, M. Sohrabi, and A. Farzaneh, "Investigation of Rock Wettability Alteration by Carbonated Water through Contact Angle Measurements," Energy and Fuels, vol. 29, no. 9, pp. 5544-5553, 2015, doi: 10.1021/acs.energyfuels.5b01069.

[13] M. Seyyedi, M. Sohrabi, and A. Sisson, "Experimental investigation of the coupling impacts of new gaseous phase formation and wettability alteration on improved oil recovery by CWI," J. Pet. Sci. Eng., vol. 150, no. June 2016, pp. 99-107, 2017, doi: 10.1016/j.petrol.2016.11.016. 
[14] A. Sanaei, A. Varavei, and K. Sepehrnoori, "Mechanistic modeling of carbonated waterflooding," SPE Symp. Improv. Oil Recover., no. April, pp. 1-19, 2018, doi: 10.2118/190319-ms.

[15] M. Sohrabi, N. I. Kechut, M. Riazi, M. Jamiolahmady, S. Ireland, and G. Robertson, "Coreflooding Studies to Investigate the Potential of Carbonated Water Injection as an Injection Strategy for Improved Oil Recovery and CO2 Storage," Transp. Porous Media, vol. 91, no. 1, pp. 101-121, 2012, doi: 10.1007/s11242-011-9835-5.

[16] N. Mosavat and F. Torabi, "Micro-optical analysis of carbonated water injection in irregular and heterogeneous pore geometry," Fuel, vol. 175, pp. 191-201, Jul. 2016, doi: 10.1016/j.fuel.2016.02.039.

[17] P. Mahzari et al., "A Comprehensive Experimental Study of Pore-Scale and Core-Scale Processes During Carbonated Water Injection Under Reservoir Conditions," SPE, pp. 1-27, 2017.

[18] T. Sabila, H. K. Ben Mahmud, W. M. Mahmud, and M. I. J. Van Dijke, "Two-Phase OilWater Empirical Correlation Models for SCAL and Petrophysical Properties in Intermediate Wet Sandstone Reservoirs," IOP Conf. Ser. Mater. Sci. Eng., vol. 495, no. 1, pp. 1-13, 2019, doi: 10.1088/1757-899X/495/1/012065.

[19] D. K. Keelan, "A Critical Review of Core Analysis Techniques," J. Can. Pet. Technol., vol. 11, no. 02, pp. 42-55, 1972, doi: 10.2118/72-02-06.

[20] E. Amott, "Observations Relating to the Wettability of Porous Rock," Pet. Trans. AIME, vol. 216, pp. 156-162, 1959.

[21] A. Al Mesmari, P. Mahzari, and M. Sohrabi, "An Improved Methodology for Simulating Oil Recovery by Carbonated Water Injection: Impact of Compositional Changes," SPE Annu. Tech. Conf. Exhib., pp. 1-21, 2016. 
Figures

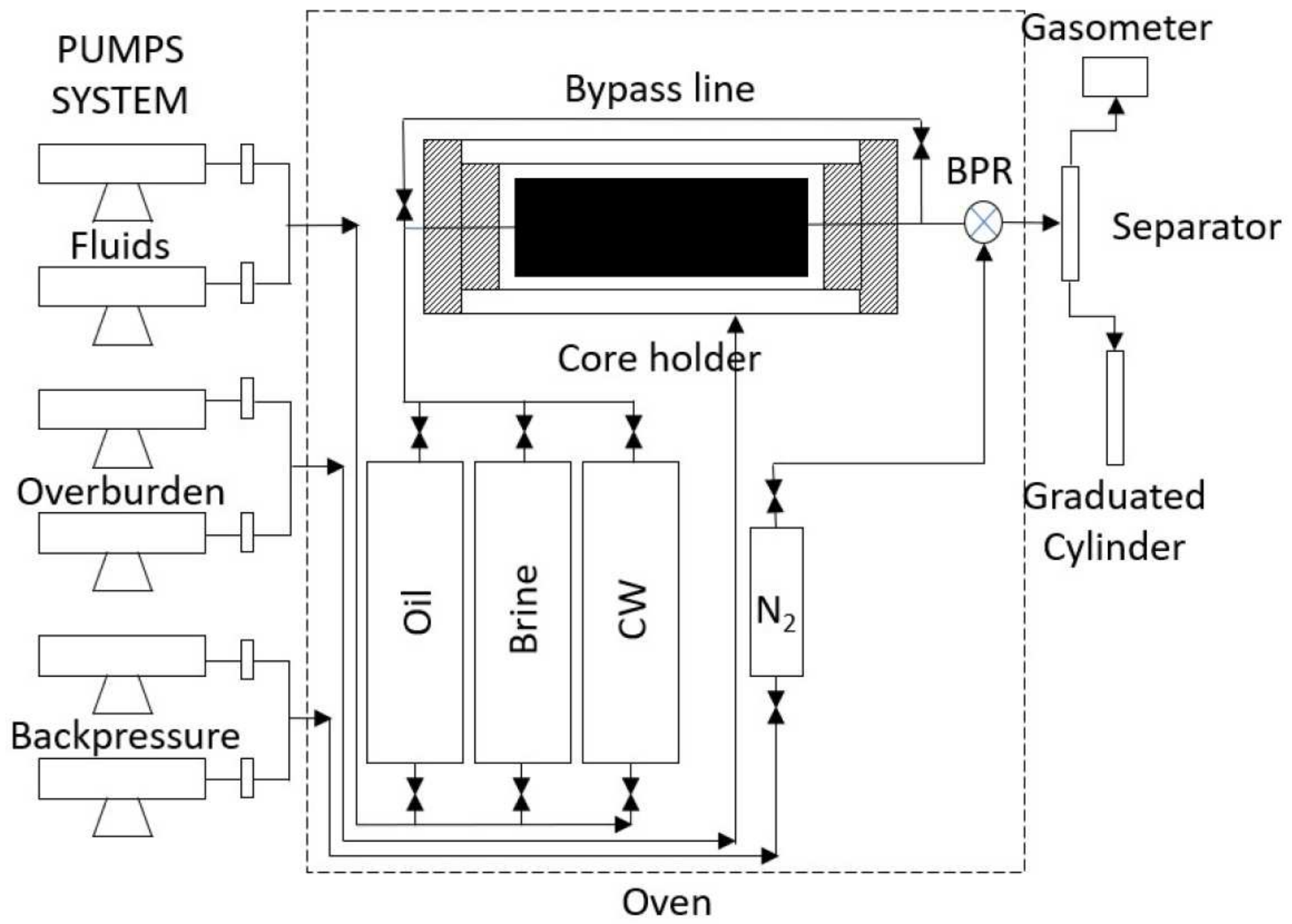

Figure 1

Schematic of the core flood rig used in the core flood experiments 


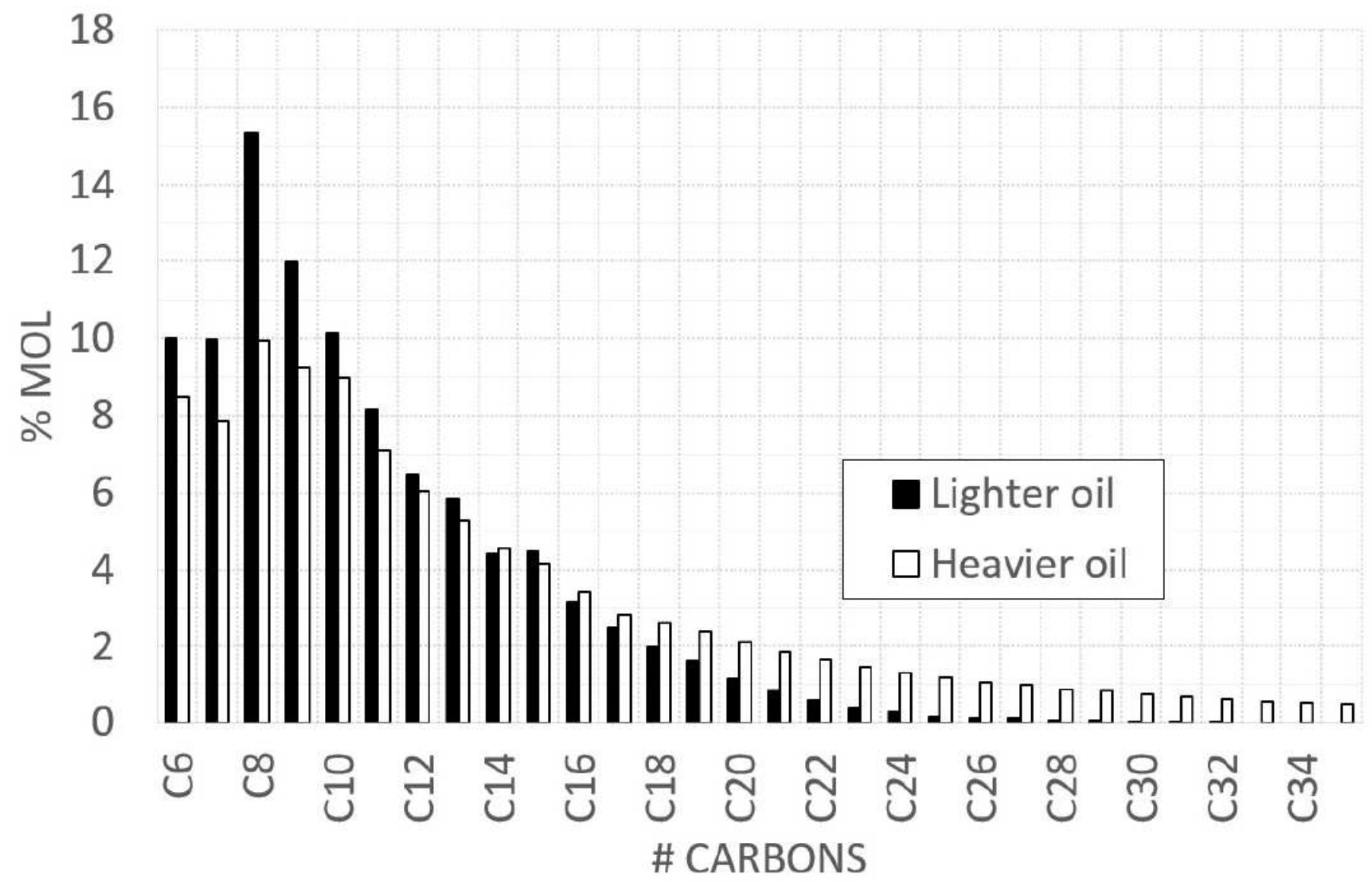

Figure 2

Compositions of the lighter and heavier dead oil 


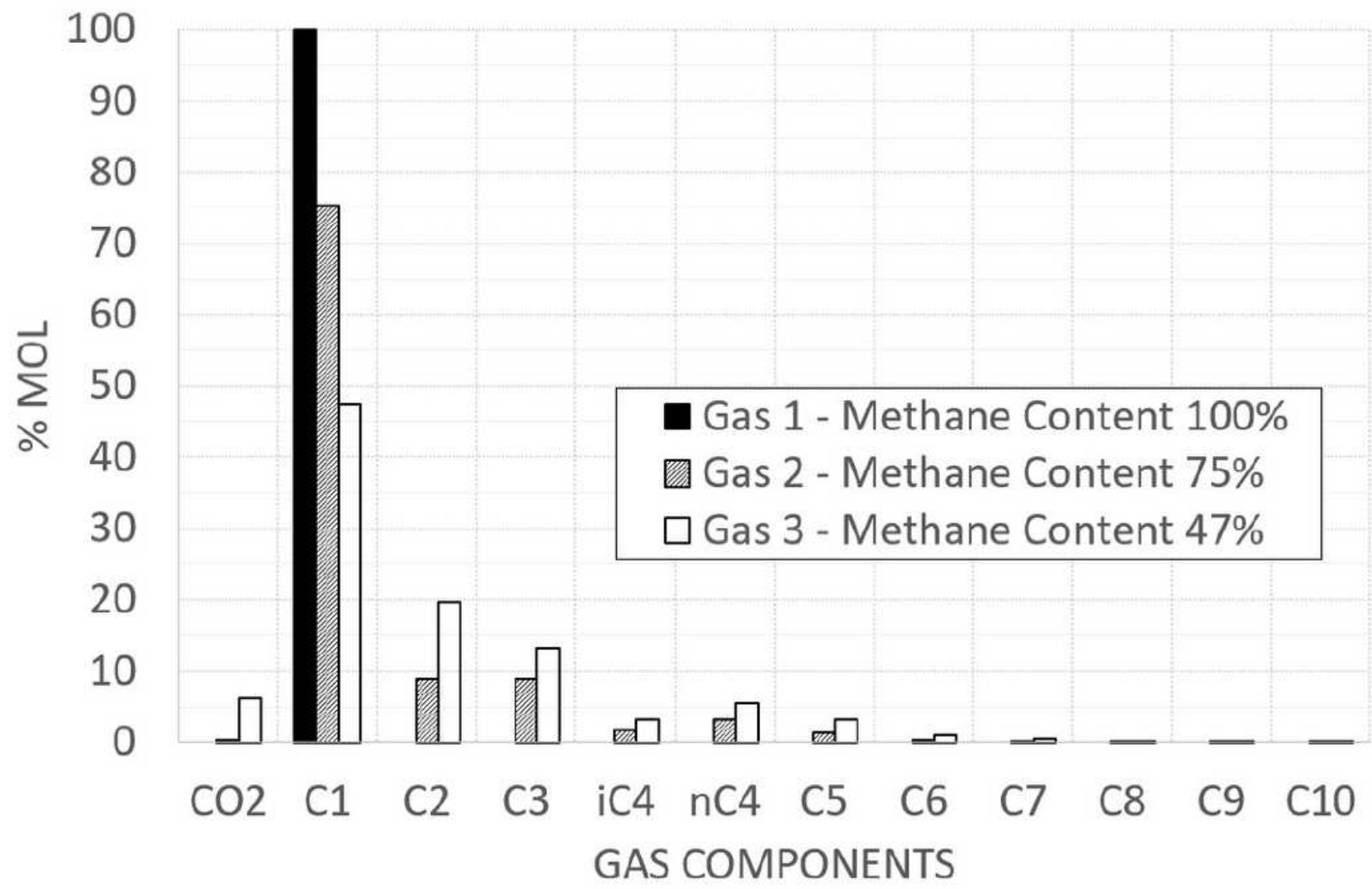

Figure 3

Gas compositions 


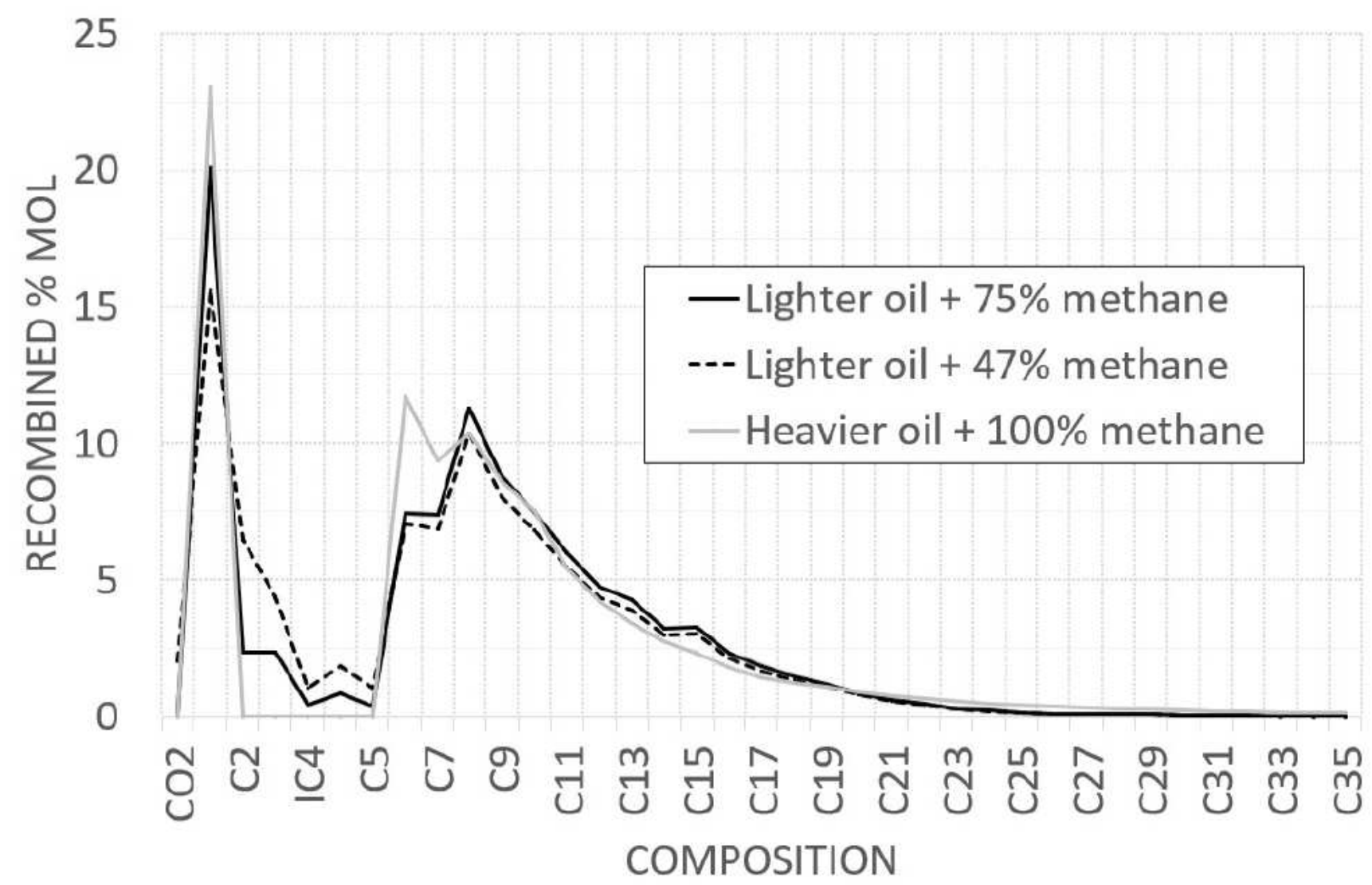

Figure 4

Compositions of the three recombined live oil used in the core flooding experiments 


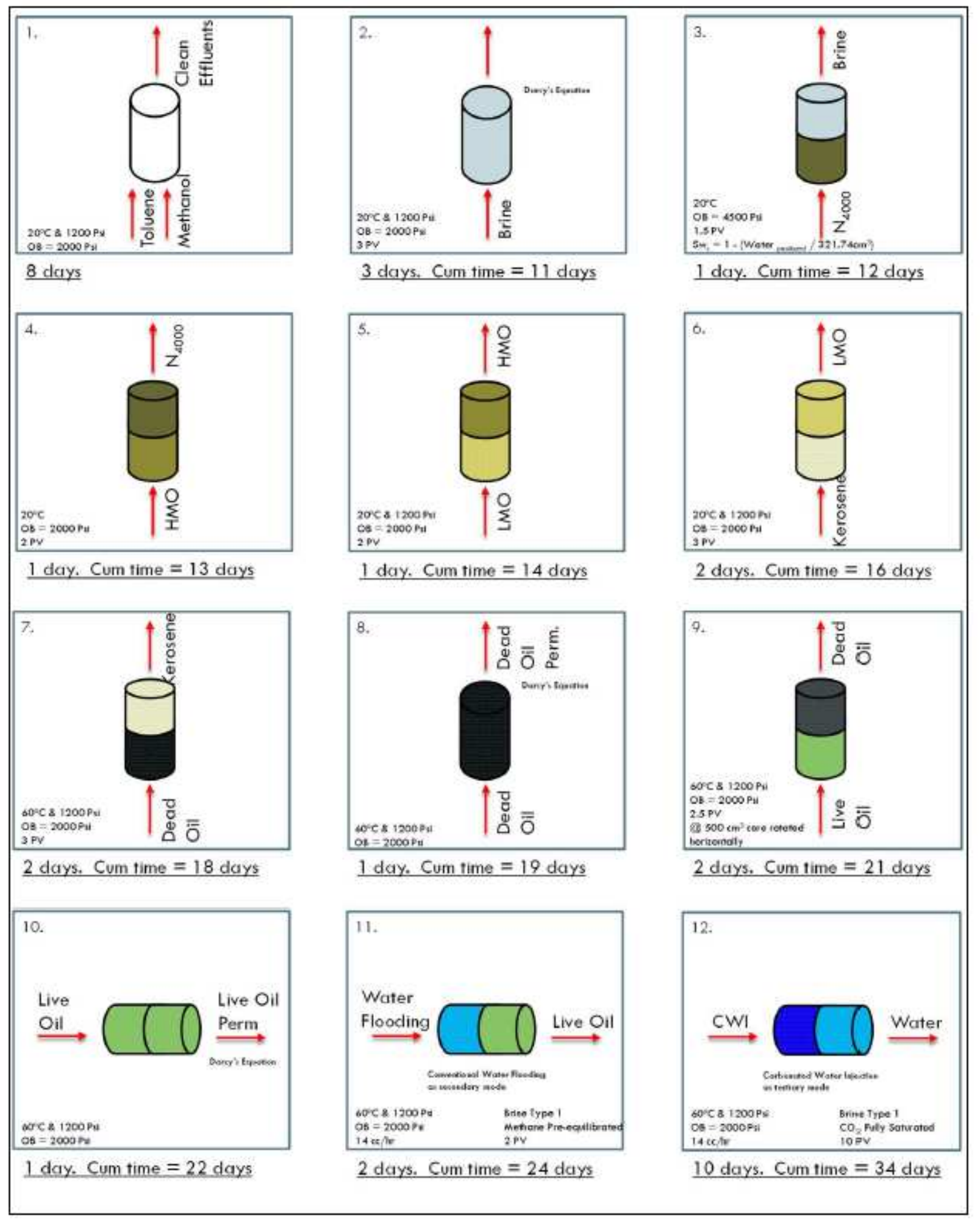

Figure 5

Core preparation for a carbonated water injection experiment under unaged conditions 


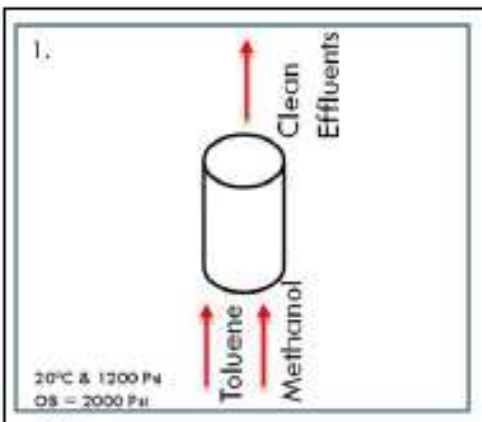

8 days

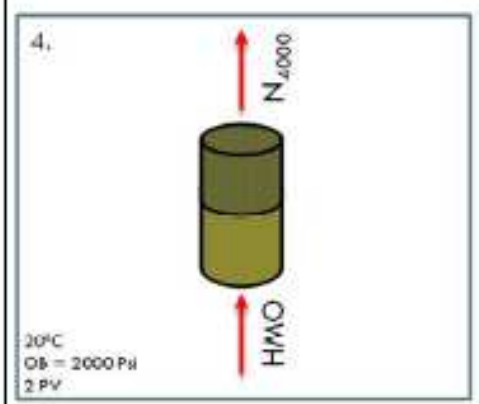

1 day, Cum time $=13$ days

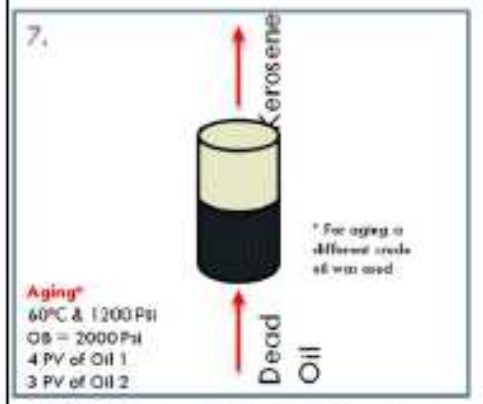

40 days. Cum time $=56$ days

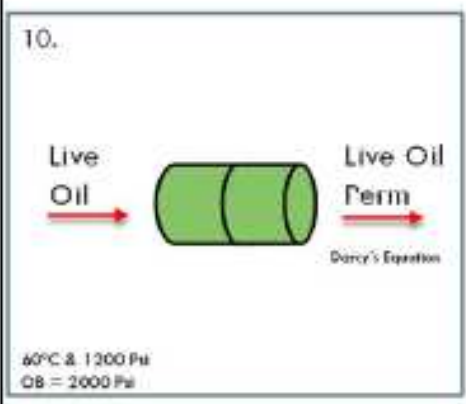

1 day. Cum time $=60$ days

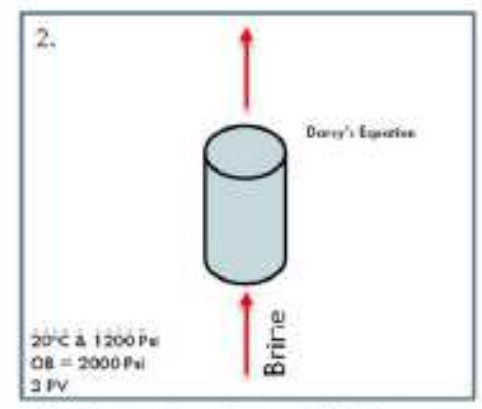

3 days Cum time $=11$ days

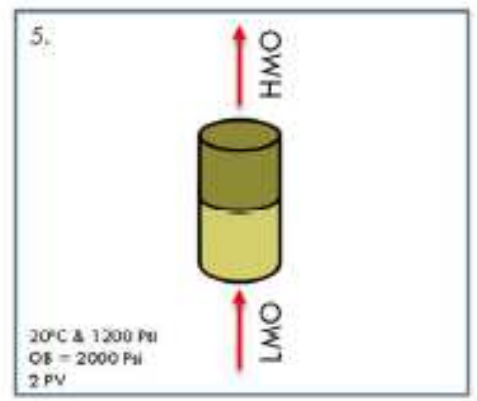

1 day. Cum time $=14$ days

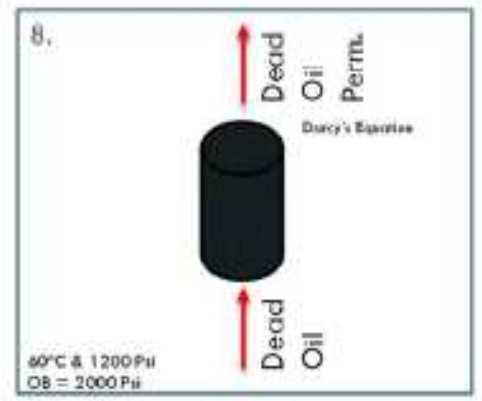

1 day com time $=57$ days

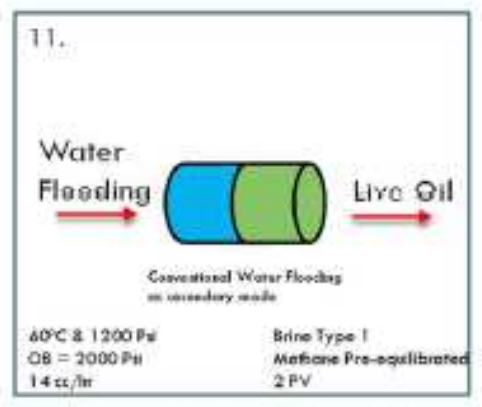

2 days. Cum time $=62$ days

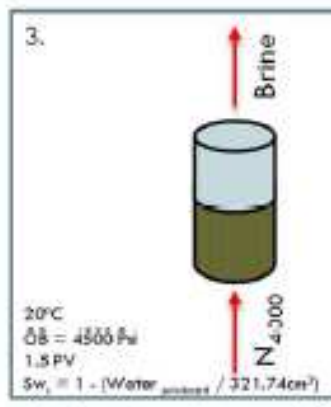

1 day. Cum time $=12$ days

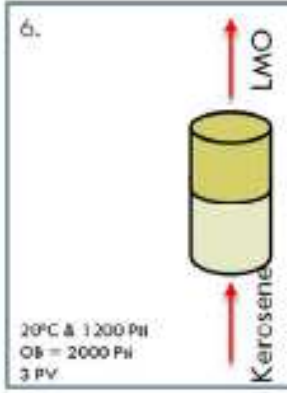

2 days. Cum time $=16$ days

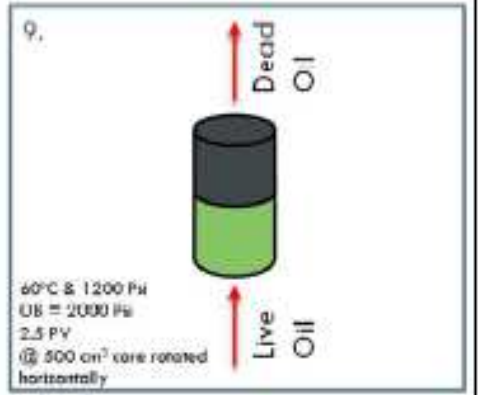

2 days. Gum time $=59$ days

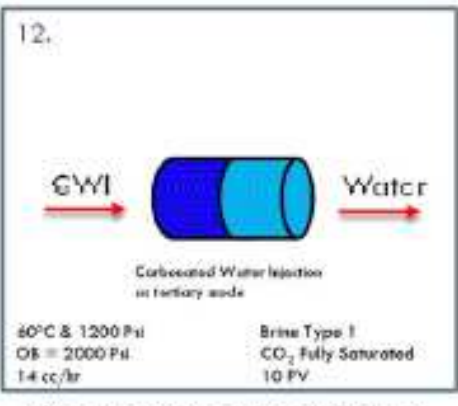

10 days. Cum time $=72$ days

\section{Figure 6}

Core preparation for a carbonated water injection experiment under aged conditions. 

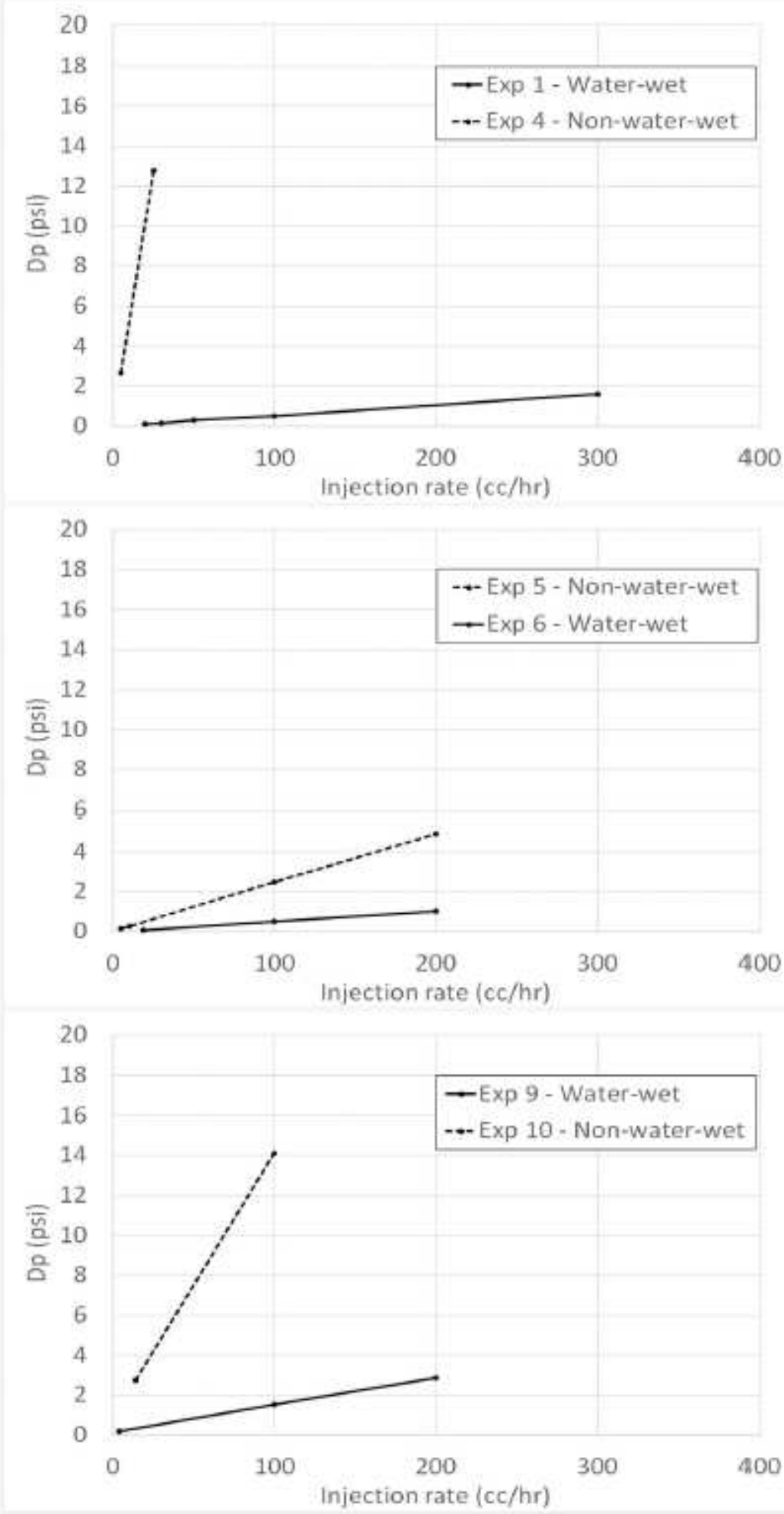

\section{Figure 7}

Differential pressure behaviour by using live oil at different injection rates. Top: heavier oil, and $100 \%$ $\mathrm{CH} 4$. Middle: lighter oil, and a multi-component gas $75 \% \mathrm{CH} 4$. Bottom; lighter oil, and a multi-component gas $47 \% \mathrm{CH} 4$. 


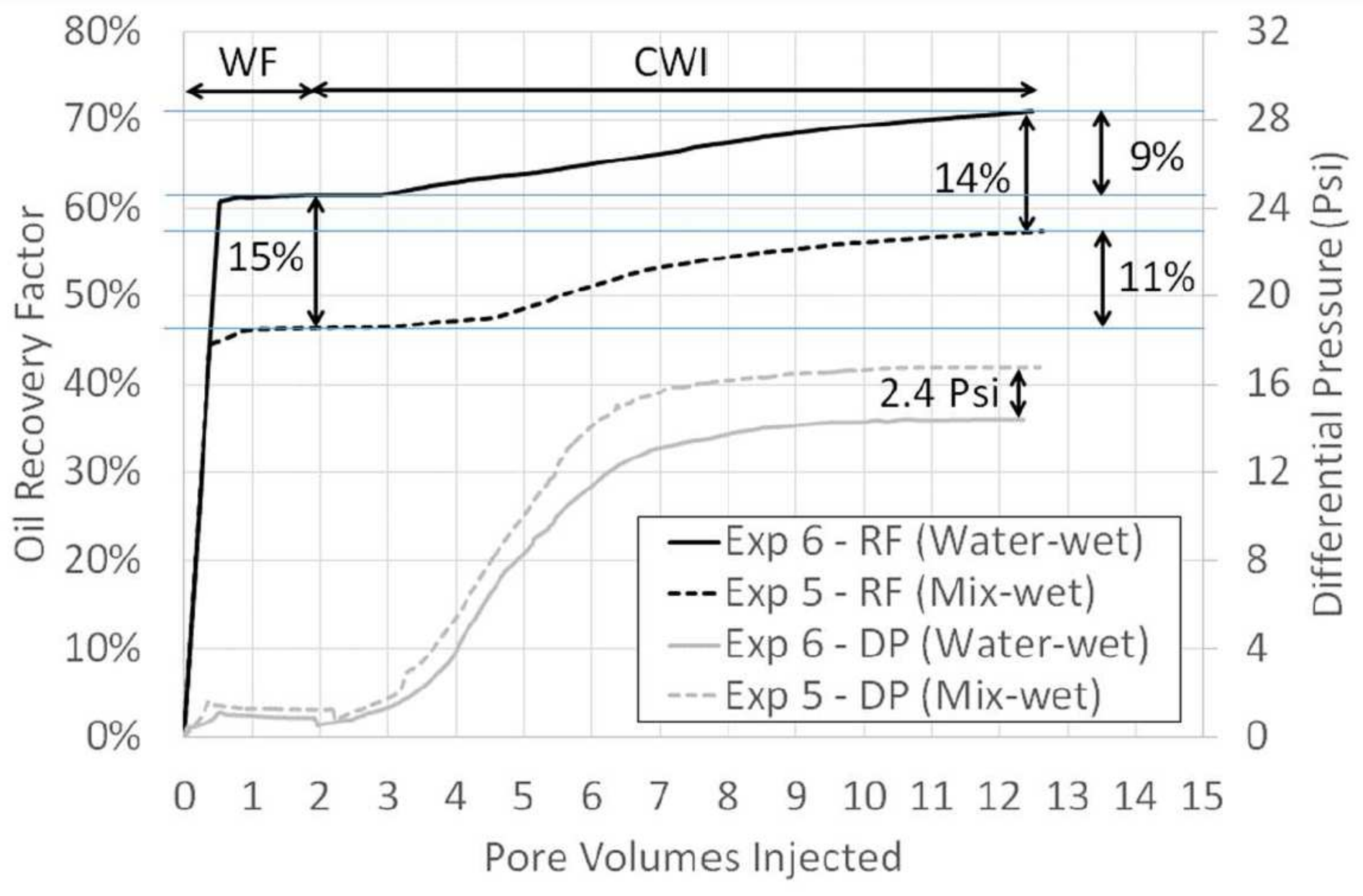

Figure 8

Experimental results for experiments 5 and 6 


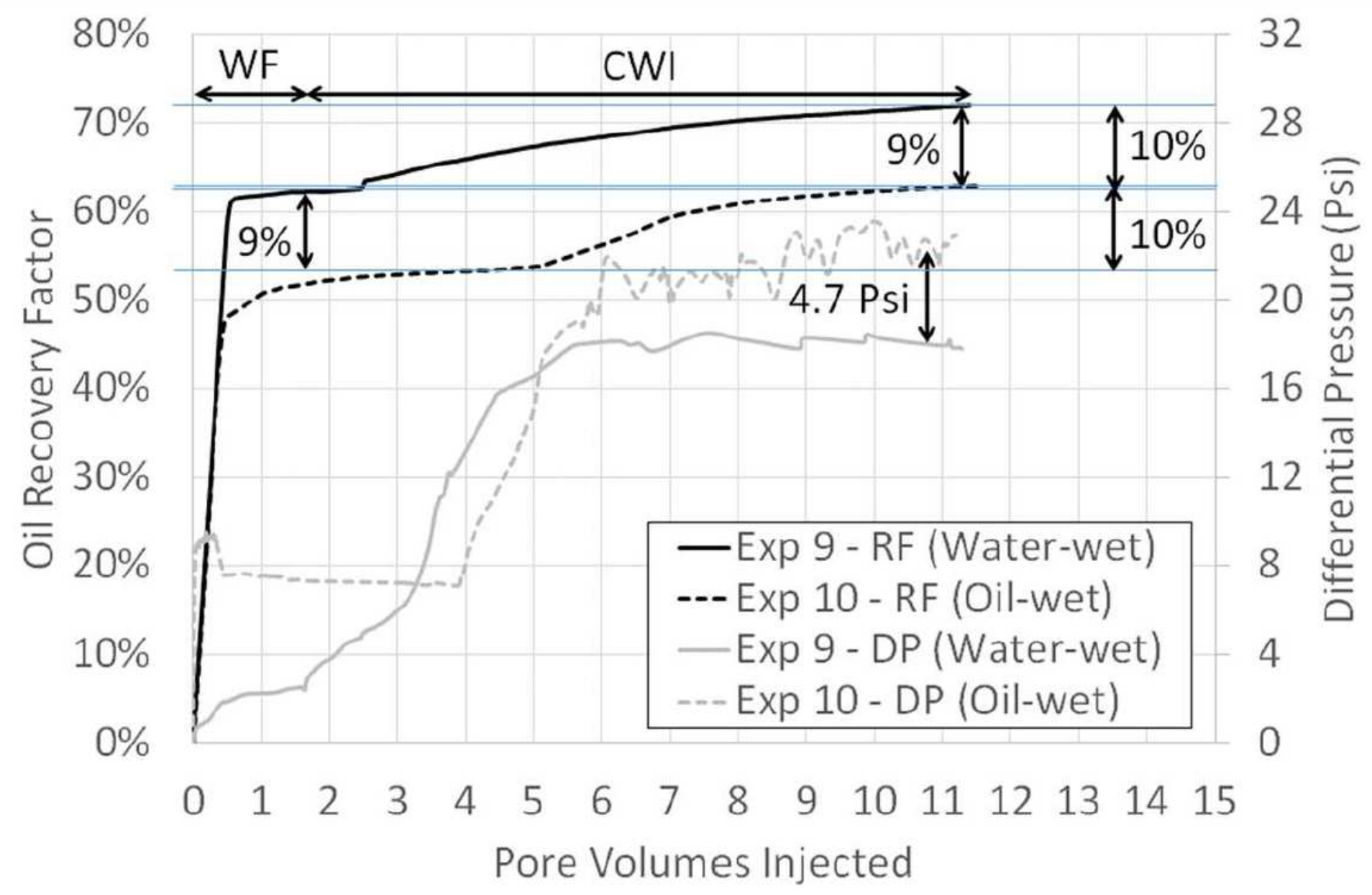

Figure 9

Experimental results for experiments 9 and 10 


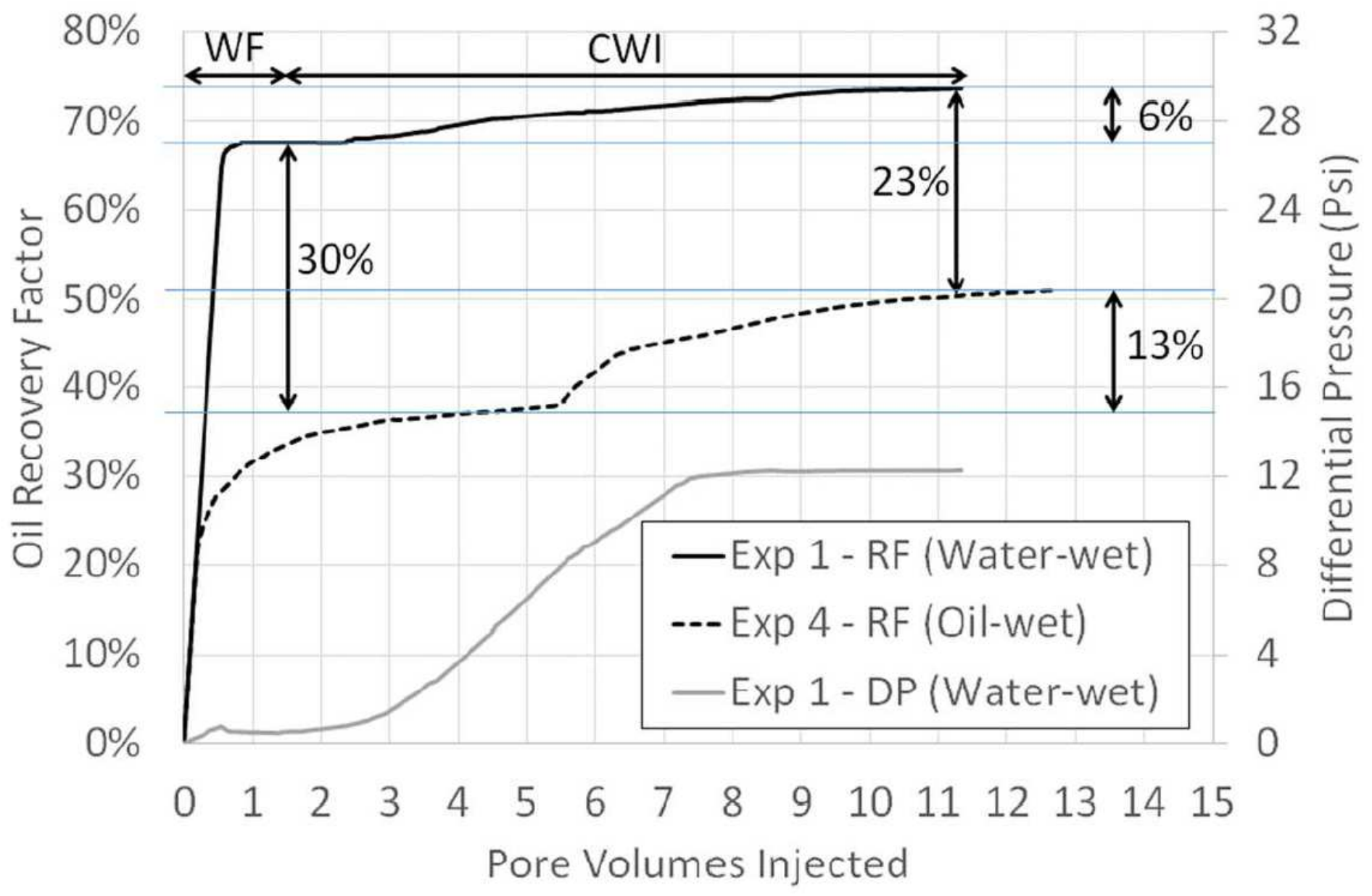

Figure 10

Experimental results for experiments 1 and 4 


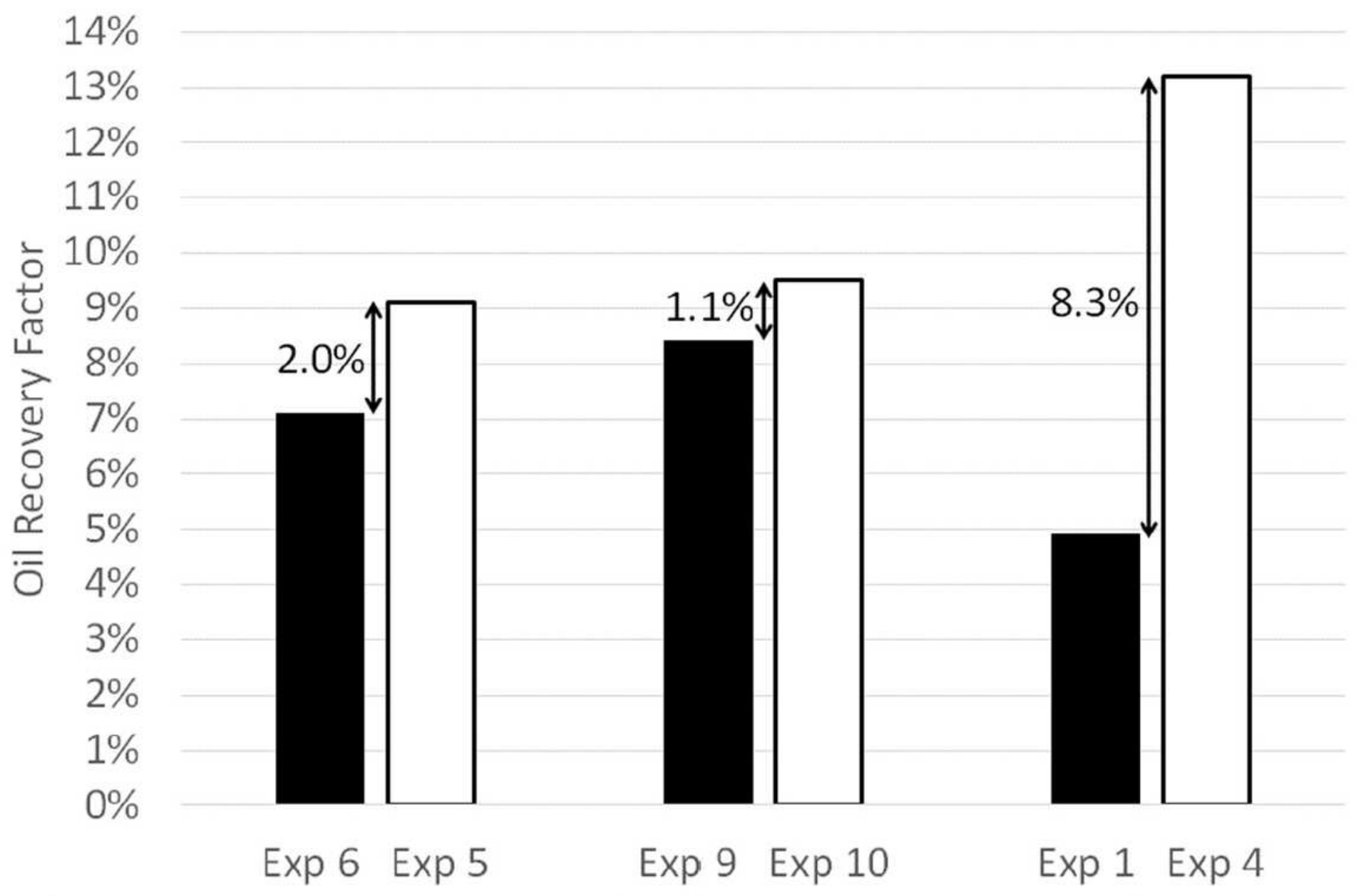

Figure 11

Oil recovery factor for the tertiary carbonated water injection scenario calculated at 7 pore volumes injected of CWI 


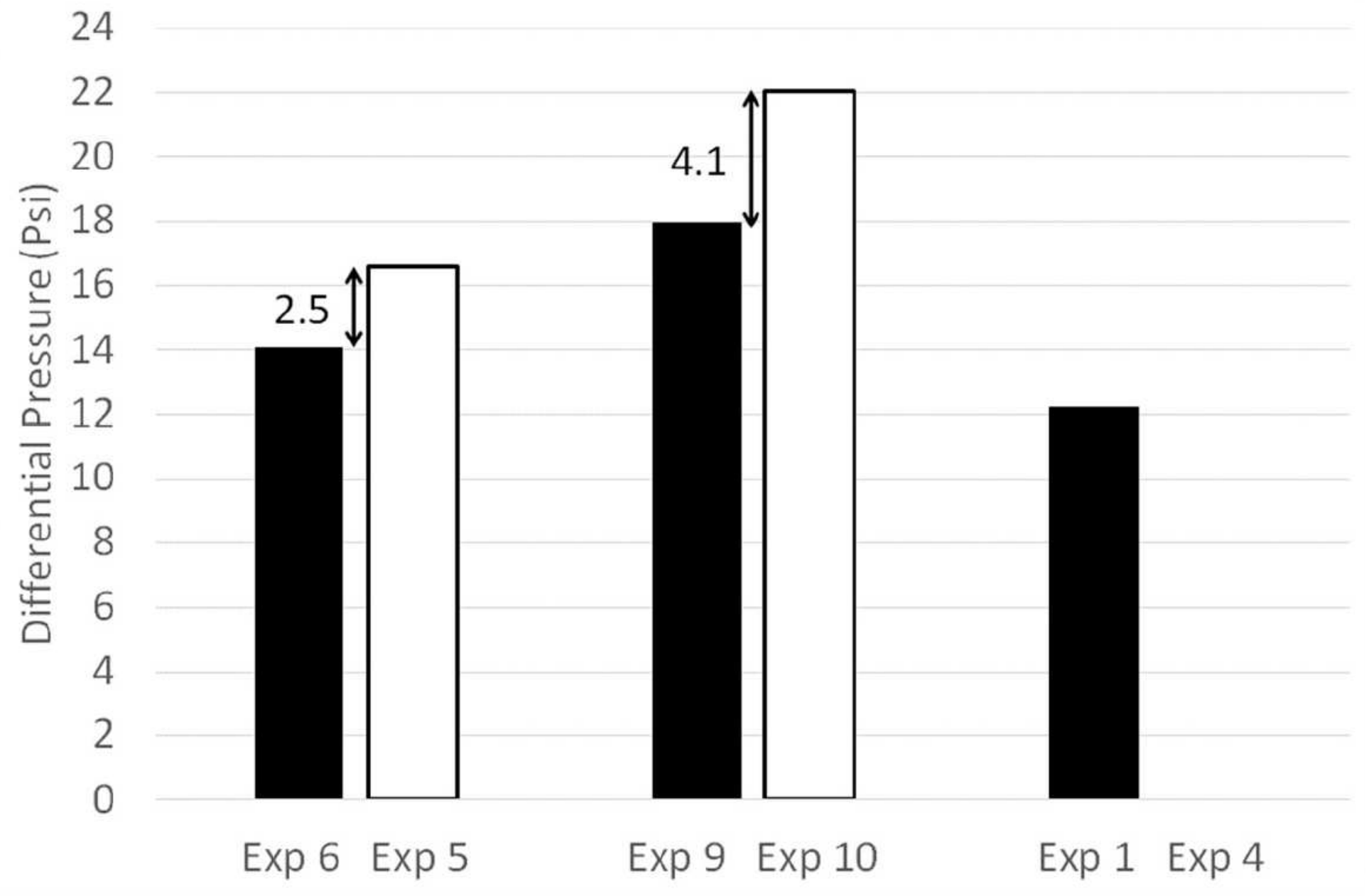

Figure 12

Differential pressure for the tertiary carbonated water injection scenario calculated at 7 pore volumes injected of CWI 
$90 \%$

$80 \%$

$70 \%$

$60 \%$

$50 \%$

$40 \%$

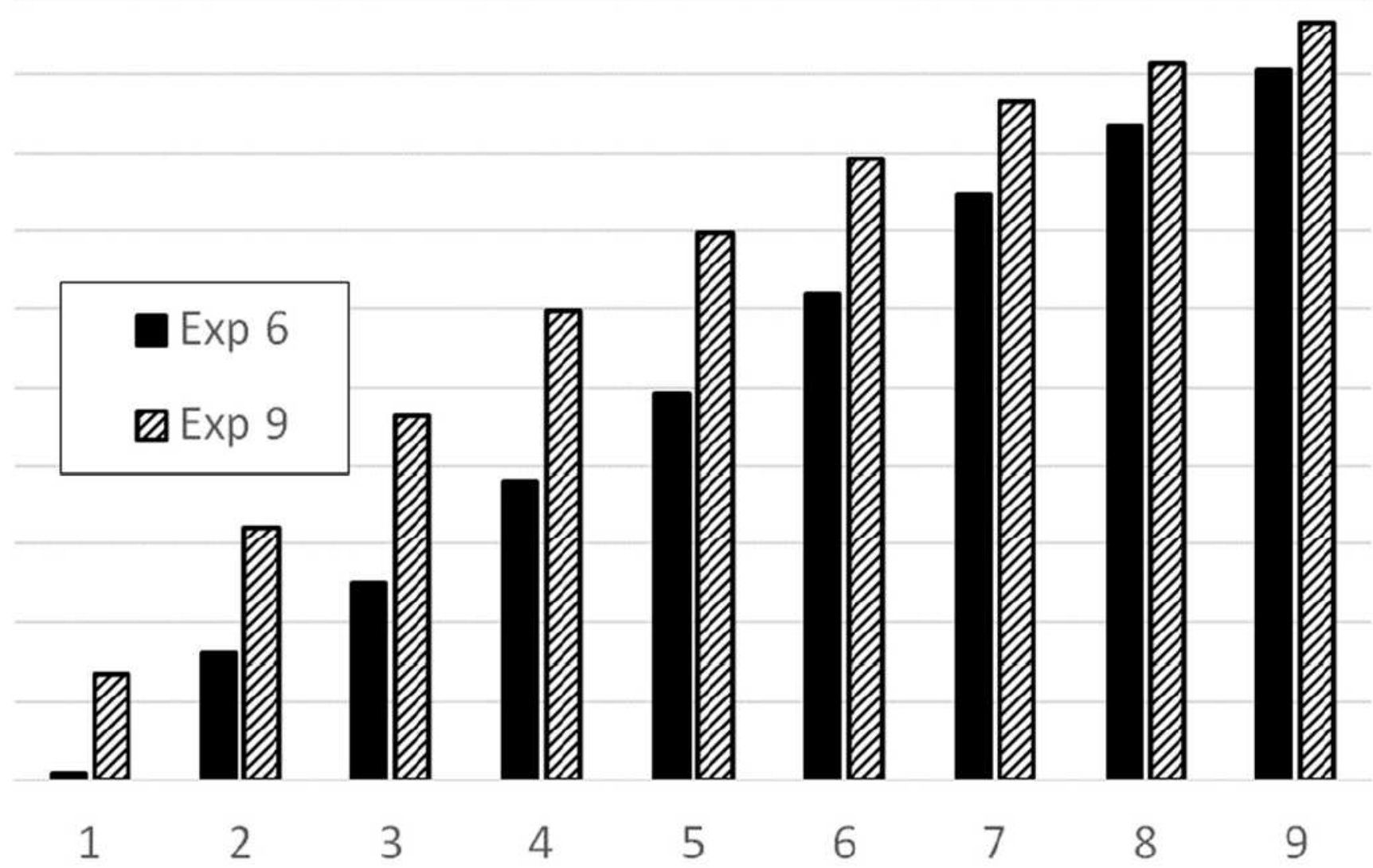

$30 \%$

$20 \%$

$10 \%$

$0 \%$

Pore Volumes Injected

Figure 13

Normalised percentage of incremental oil production recovered in the tertiary CWI for water-wet experiments 


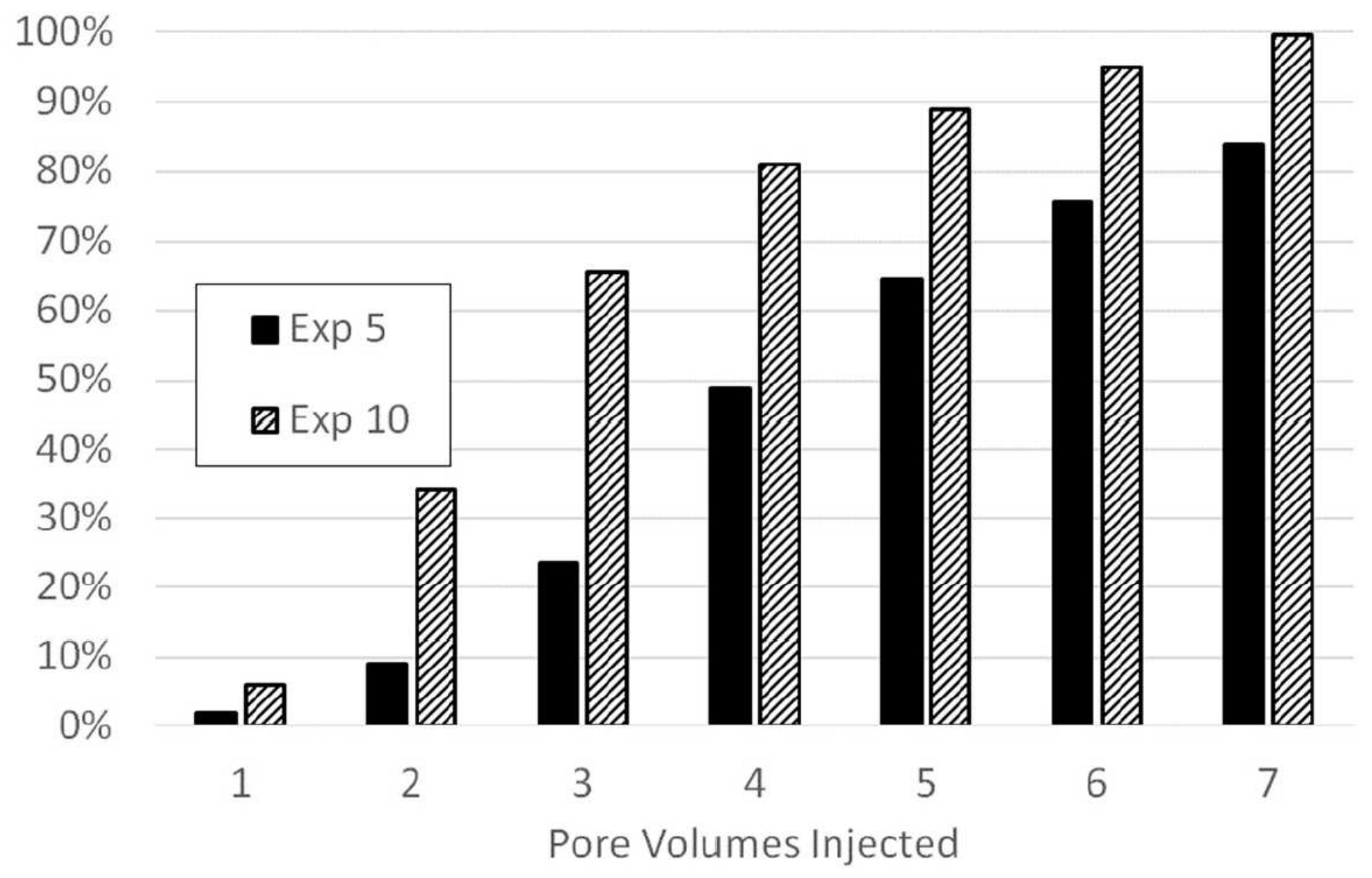

Figure 14

Normalised percentage of incremental oil production recovered in the tertiary CWI for mix/oil-wet experiments 


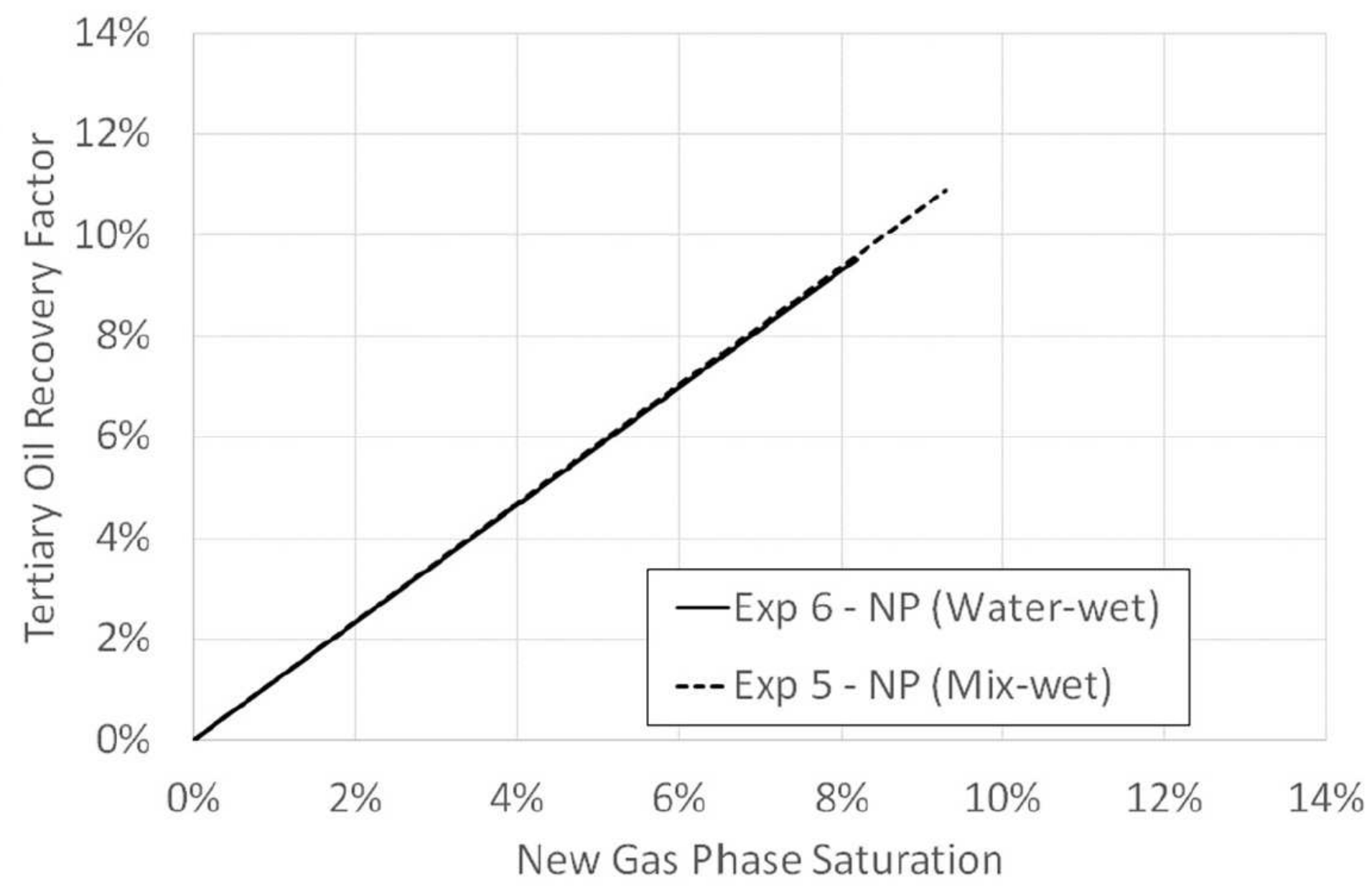

Figure 15

New gas phase saturation versus tertiary oil recovery for experiments with $20 \%$ of methane content in the recombined oil 


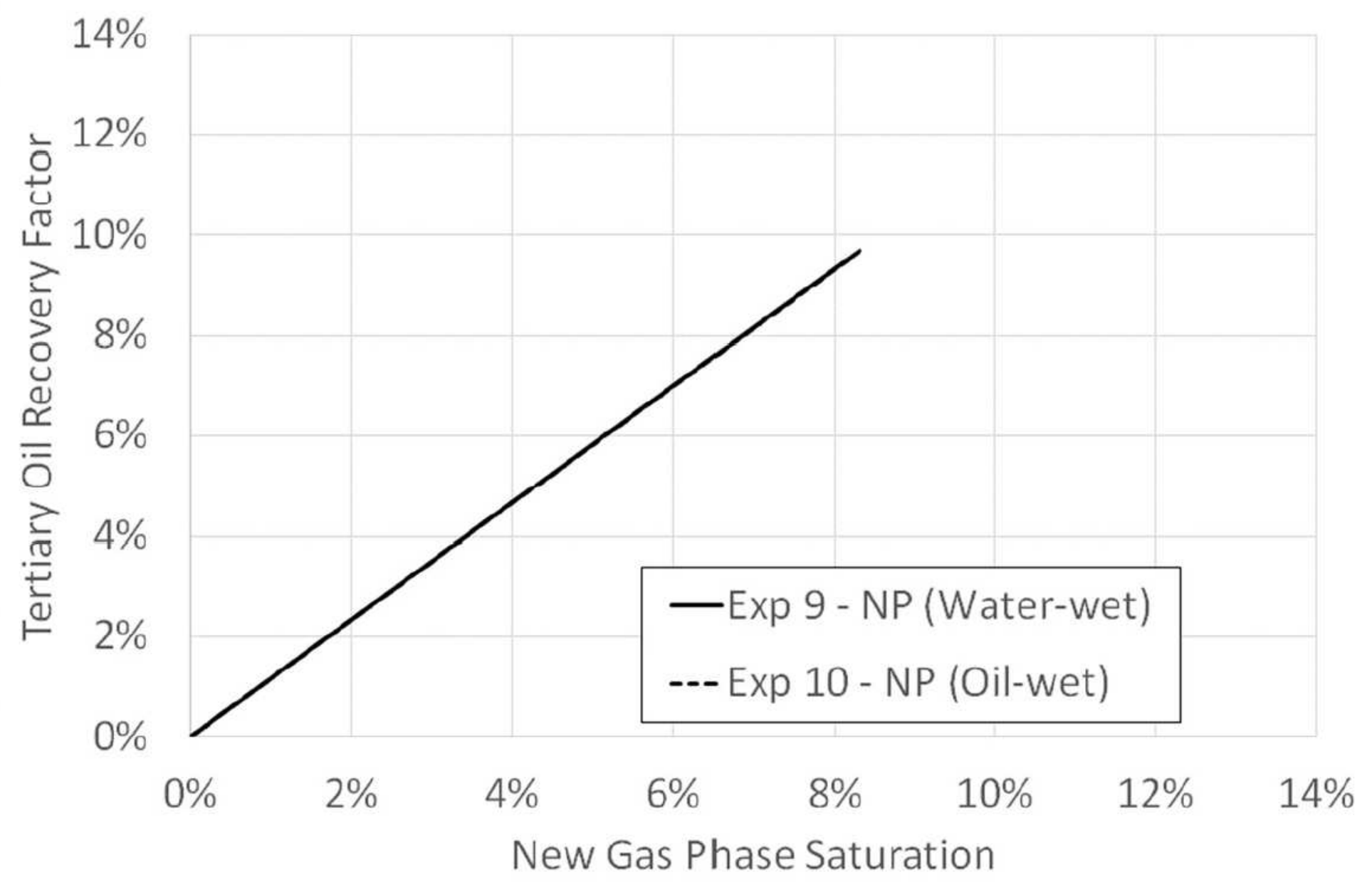

Figure 16

New gas phase saturation versus tertiary oil recovery for experiments with $16 \%$ methane content in the recombined oil 


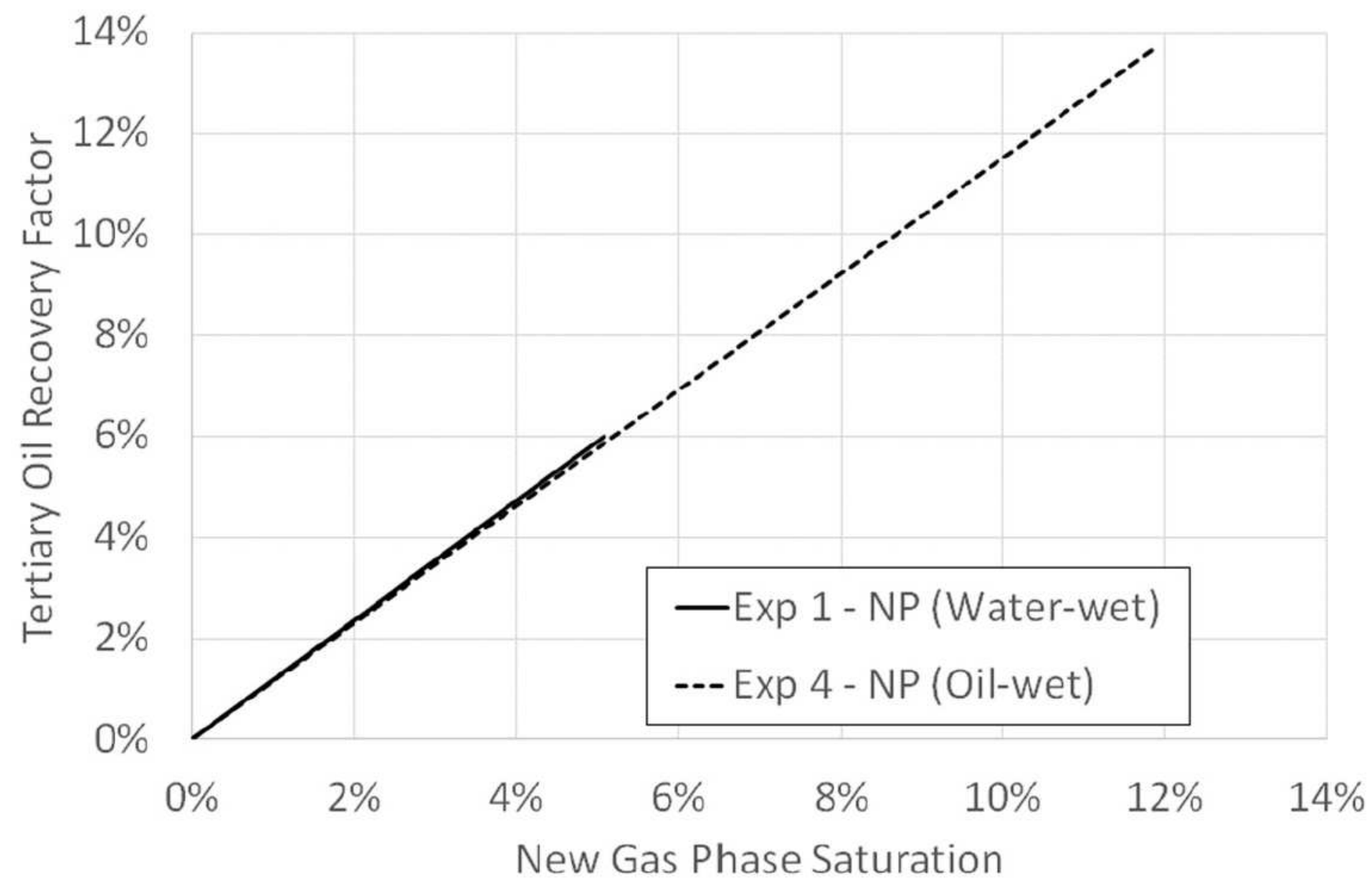

Figure 17

New gas phase saturation versus tertiary oil recovery for experiments with $23 \%$ methane content in the recombined oil 


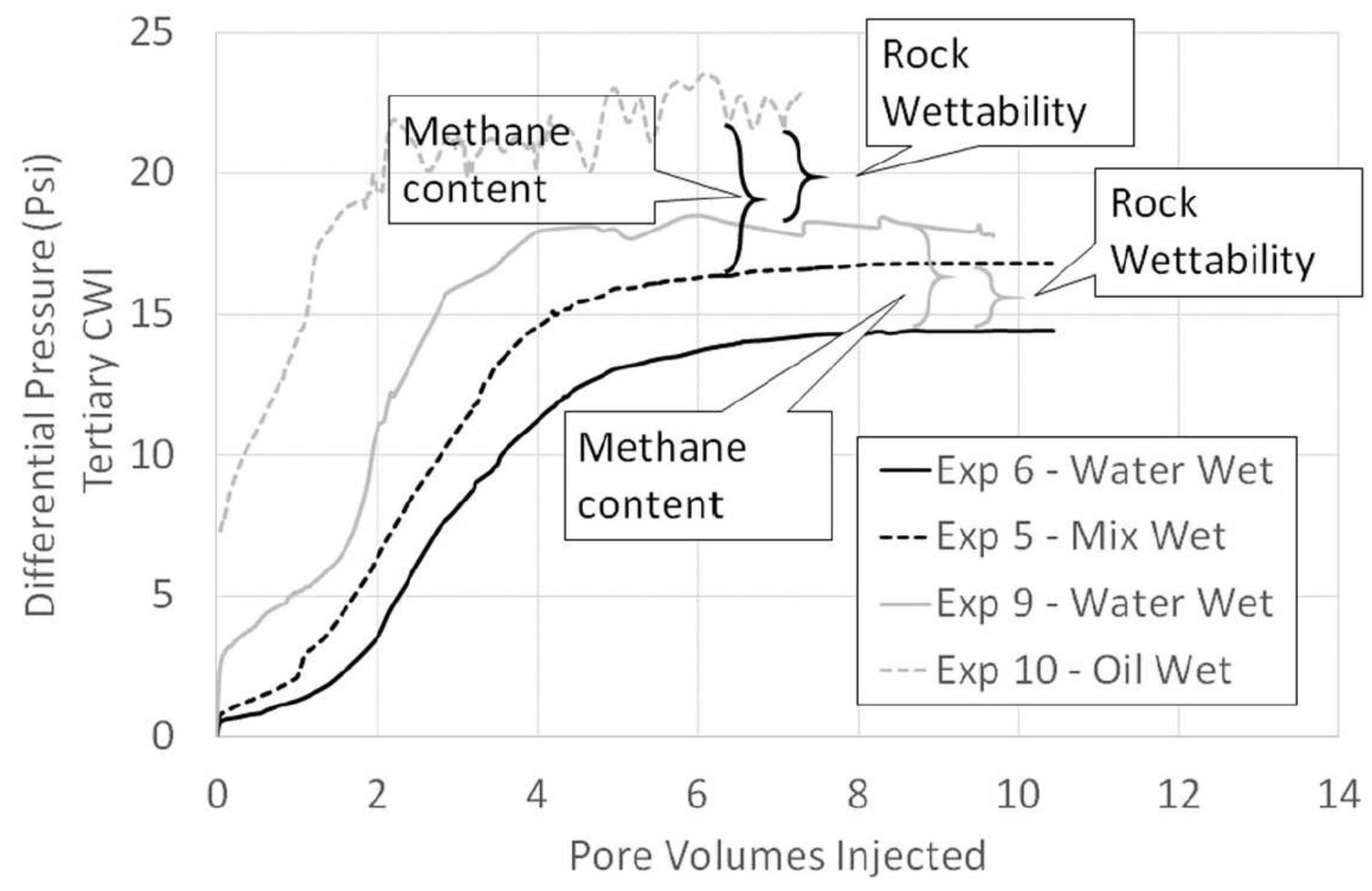

Figure 18

Effect of the methane content, and rock wettability on the tertiary differential pressure 


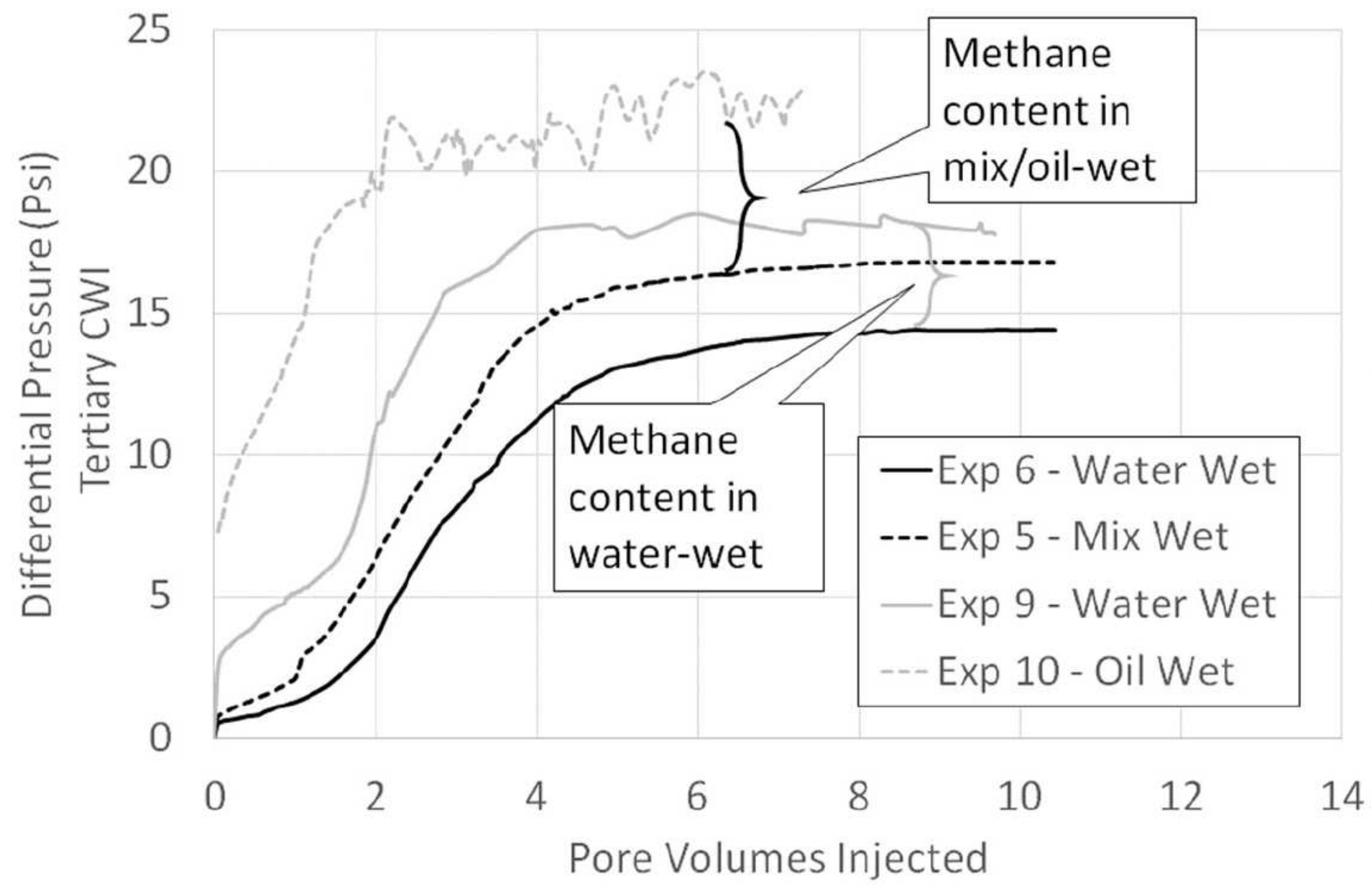

Figure 19

Effect of the methane content in mix/oil-wet, and water-wet systems on the differential pressure 


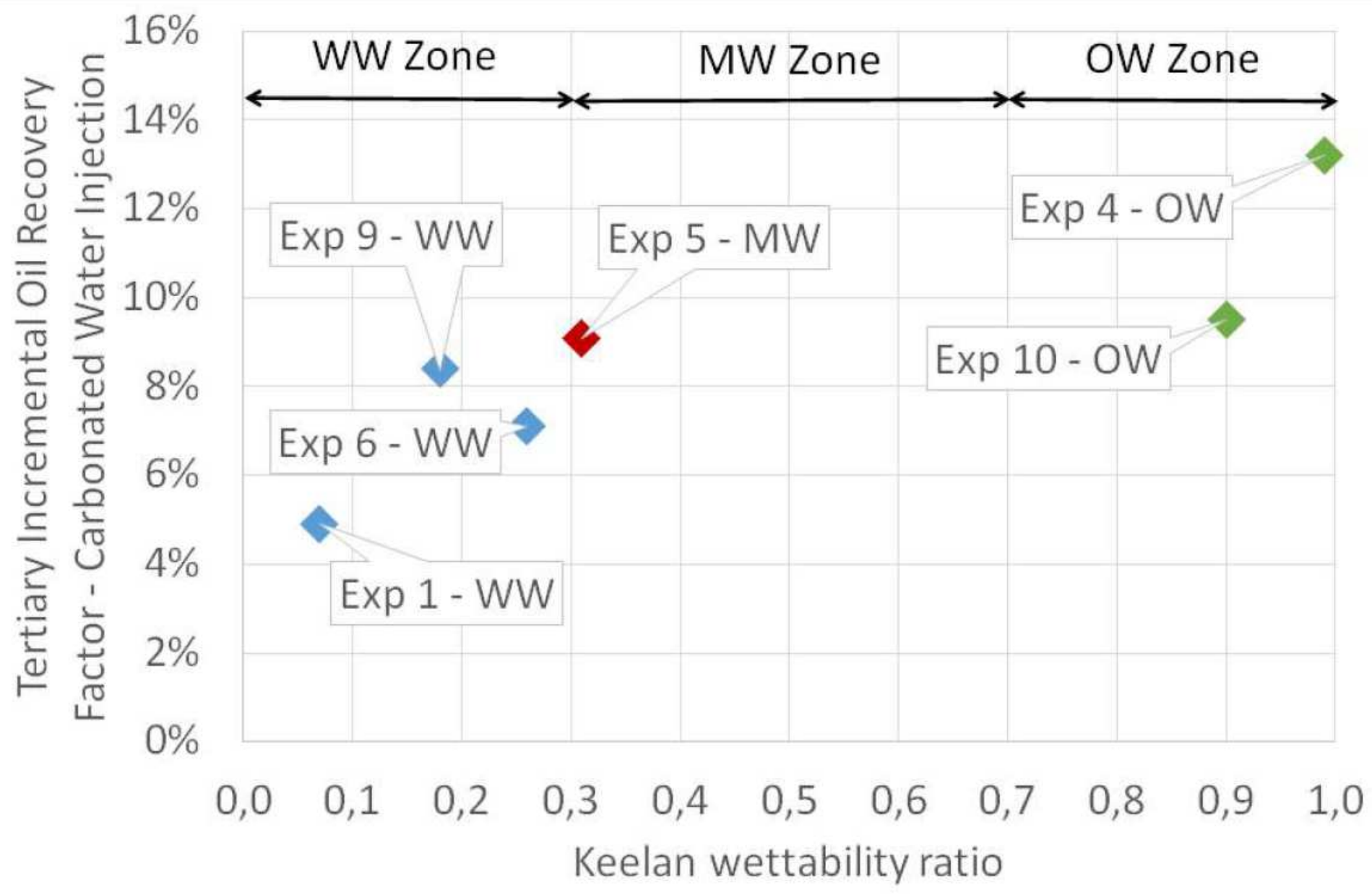

Figure 20

Relationship between Keelan ratio, and tertiary incremental oil recovery factor associated to carbonates water injection. Abbreviations mean WW (water-wet), MW (mix-wet), and OW (oil-wet) 